\title{
The Role of the Architect: Changes of the Past, Practices of the Present, and Indications of the Future
}

Chad B. Jones

Brigham Young University - Provo

Follow this and additional works at: https://scholarsarchive.byu.edu/etd

Part of the Construction Engineering and Management Commons

\section{BYU ScholarsArchive Citation}

Jones, Chad B., "The Role of the Architect: Changes of the Past, Practices of the Present, and Indications of the Future" (2006). Theses and Dissertations. 395.

https://scholarsarchive.byu.edu/etd/395

This Thesis is brought to you for free and open access by BYU ScholarsArchive. It has been accepted for inclusion in Theses and Dissertations by an authorized administrator of BYU ScholarsArchive. For more information, please contact scholarsarchive@byu.edu, ellen_amatangelo@byu.edu. 
THE ROLE OF THE ARCHITECT: CHANGES OF THE PAST, PRACTICES OF THE PRESENT, AND INDICATIONS OF THE FUTURE

By

Chad B. Jones

A thesis submitted to the faculty of

Brigham Young University

in partial fulfillment of the requirements for the degree of

Master of Science

School of Technology

Brigham Young University

April 2006 
BRIGHAM YOUNG UNIVERSITY

GRADUATE COMMITTEE APPROVAL

of a thesis submitted by

Chad B. Jones

This thesis has been read by each member of the following graduate committee and by majority vote has been found to be satisfactory.

Date

Date

Date
Kevin L. Burr, Chair

Jay P. Christofferson, Member

Kevin R. Miller, Member 


\title{
BRIGHAM YOUNG UNIVERSITY
}

\section{FINAL READING APPROVAL}

I have read the thesis of Chad B. Jones in its final form and have found that (1) its format, citations, and bibliographical styles are consistent and acceptable and fulfill university and department style requirements; (2) its illustrative materials including figures, tables, and charts are in place; and (3) the final manuscript is satisfactory to the graduate committee and is ready for submission to the university library.

Date

Kevin L. Burr

Chair, Graduate Committee

Approved for the Department

Val D. Hawks

Graduate Coordinator, School of Technology

Accepted for the College

\author{
Alan Parkinson \\ Dean, Ira A. Fulton College of Engineering and \\ Technology
}




\begin{abstract}
THE ROLE OF THE ARCHITECT: CHANGES OF THE PAST, PRACTICES OF THE PRESENT, AND INDICATIONS OF THE FUTURE
\end{abstract}

\author{
Chad B. Jones \\ School of Technology \\ Master of Science
}

For centuries the architect was the master builder; the one who was responsible for both the design and the construction of a project with sufficient construction expertise to oversee the project from inception to completion. Eventually, complexity of projects required a higher level of specialization leading to the separation of the designer and the builder. Since that separation, the role of the designer, or architect, has continued to shift and evolve.

In recent history, the architect has been the one selected by a building owner, at the inception of the project, as the professional who is able to assist and represent the owner throughout the duration of the project. Today however, the role of the architect is once again shifting and leading the architect in a different direction. Building owners are beginning to approach the builder through a design-build or construction manager 
delivery method first and relying upon them for the overall project and construction expertise instead of the architect.

The architect will continue to carry the responsibility of creating the building's design and producing the construction documents. It is very unlikely that this role will change. Any of its other construction related roles, however, are being assumed by the build team. If the architect remains on its current path, it will continue to become more specialized with design and production and carry less responsibility.

While the exact role of the architect of today is unclear and heading in a negative direction, the entire construction process continues to evolve and provide new opportunities. The successful architect to come is going to be the one who looks at ways to reclaim its lost responsibilities, explore new alternative services, and promote a higher level of collaboration with the build team. 


\section{ACKNOWLEDGEMENTS}

Upon completion of this research topic, I wish to express my gratitude and appreciation of the professors and graduate committee for their guidance and direction, the panel

members for their insight and commitment to the research project, and my family, wife, and friends for their constant support and encouragement. 


\section{TABLE OF CONTENTS}

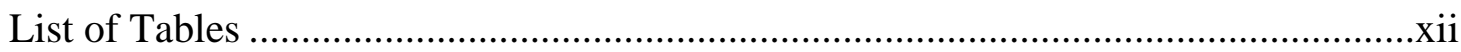

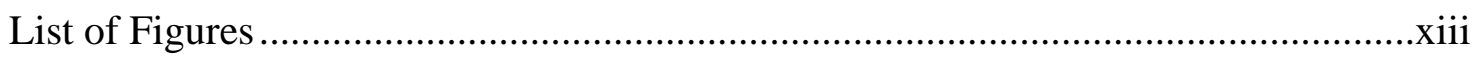

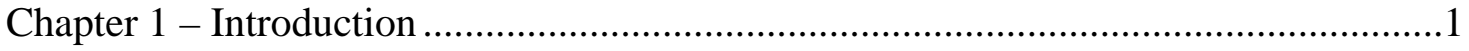

Background of the Problem .............................................................................

Statement of the Problem .................................................................................

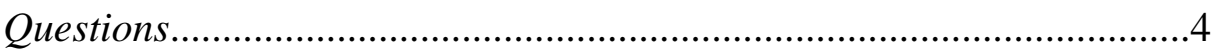

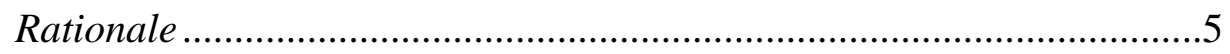

Purpose of the Research ………………………………….................................

Research Objectives...............................................................................

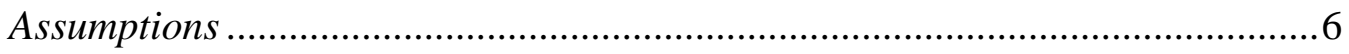

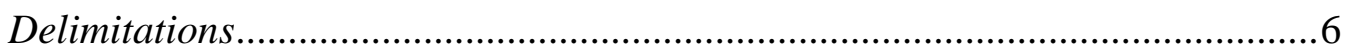

Definitions............................................................................................

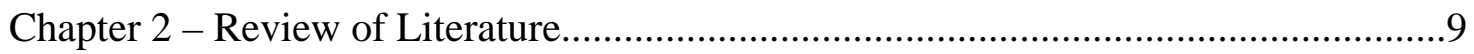

Ancient History of the Architect........................................................................

Ancient Greece and the Origins..............................................................

Ancient Rome and the Architect...............................................................10

Europe and the Dark Ages...................................................................11

Emergence from the Dark Ages - The Renaissance …..............................11

Modern History of the Architect ..........................................................................12 
Eighteenth Century America. 1

Nineteenth Century - Establishment \& Development of the Architect ....13

Nineteenth Century - Professionalism...............................................14

Nineteenth Century - Education .......................................................15

Twentieth Century - Business Practices..............................................16

Twentieth Century - Coping with Growth..............................................17

Twentieth Century - Organizational Structure of the Office ...................17

Into the Twenty First Century ...............................................................19

The Builder in American History ................................................................19

The Construction Manager in American History ..............................................20

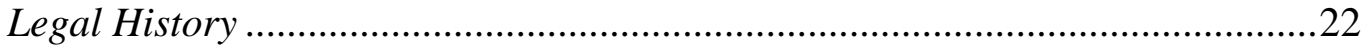

Current Roles in the Construction Process .....................................................22

The Architect of Today ....................................................................23

The Construction Manager of Today....................................................25

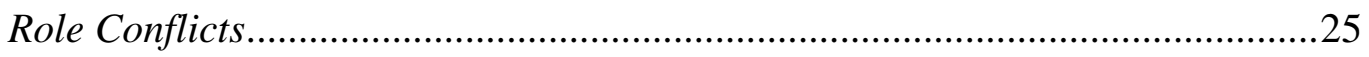

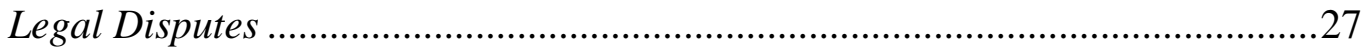

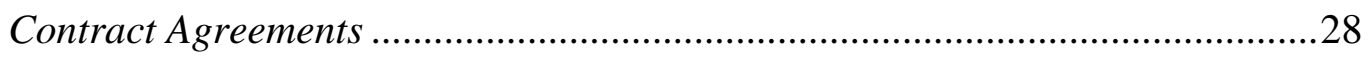

Construction Expertise of the Architect.............................................................28

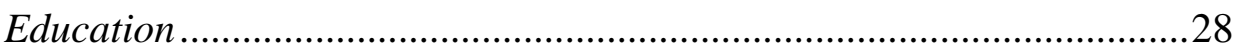

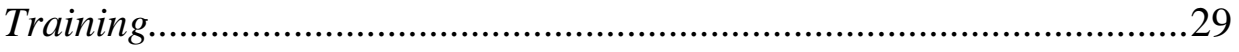

Industry Perception of the Architect ...............................................................30

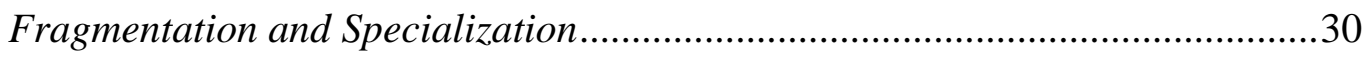

Delivery Methods and the Role of the Architect ................................................31 
Design-Bid-Build

Design-Build

Bridging

CM at Risk. .36

Insights of Tomorrow

Project Definition and Rotation. .37

A Return to the Master Builder .38

Chapter 3 - Methodology

The Method .41

The Process.

Step One - Selection of the Panel Members .42

Step Two - Development of the First Round Delphi Statements

Step Three - Testing the Statements ..... .44

Step Four - Administration of the First Statements. .44

Step Five - Analysis of the first round .44

Step Six - Preparation of the Second Round Statements .44

Step Seven - Administration of the Second Statements ....... .45

Step Eight - Third Round Statements .45

Chapter 4 - Findings

Historical Background. .47

The Current Definition of the Architect.

The Current Role of the Architect..... .50

The Architect and the Design Phase..... .52 
Roles during the Construction Phase

Education of the Architect .................................................................54

Factors Impacting the Architect ………………………...............................56

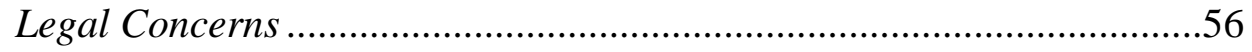

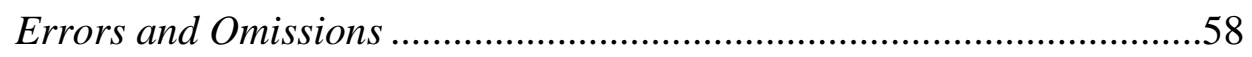

Conflicts and Communication.............................................................61

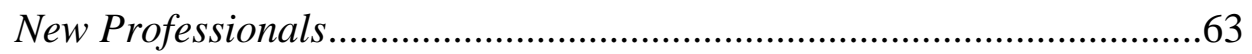

Additional Impacts ...........................................................................66

Indications into the Future of the Role of the Architect........................................67

Building Owner ...................................................................................67

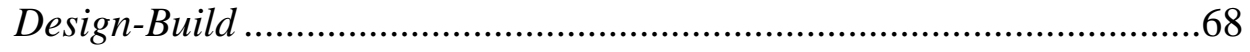

Fragmentation and Specialization .........................................................69

Design vs. Production Architect ..............................................................71

Additional Comments .............................................................................71

Chapter 5 - Conclusions and Recommendations........................................................75

The Architect of Today ……………………………………...............................75

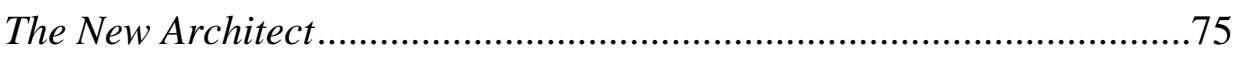

Factors Impacting the New Architect .....................................................75

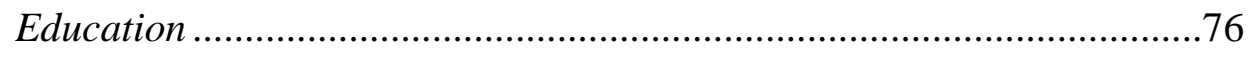

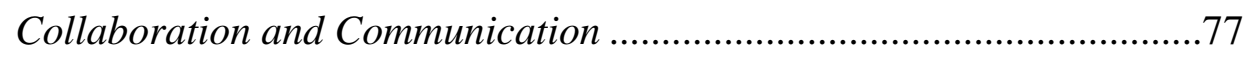

The Architect of Tomorrow ............................................................................79

Indications of the Direction of the Architect..............................................80

Suggestions to Improve the Direction of the Architect ...............................81 
Recommendations for the Industry ..........................................................82

Recommendations for Additional Study .......................................................84

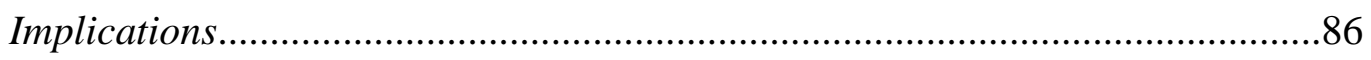

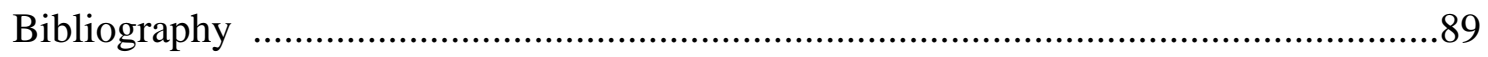

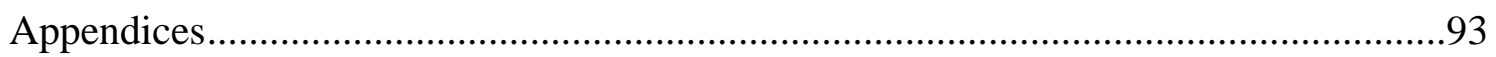

Appendix A - Selected Panel Members .................................................................95

Appendix B - Delphi Questions .....................................................................97 


\section{LIST OF TABLES}

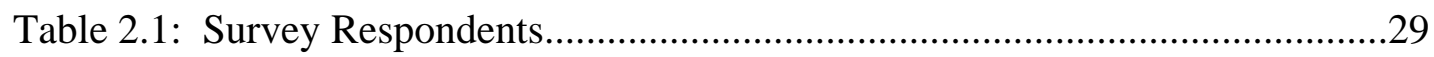

Table 2.2: Design-Build vs. Design-Bid-Build...................................................33

Table 2.3: Errors and Omissions Claims for Design-Build ..................................34 


\section{LIST OF FIGURES}

Fig. 2.1 - Construction Project Organizational Chart..............................................23

Fig. 2.2 - Position of the Program Manager ...........................................................38

Fig. 4.1: Difference in the Current Role of the Architect ....................................49

Fig. 4.2: More Suitable Definition of the Architect Today....................................50

Fig. 4.3: Qualified Professional for Construction Administration............................52

Fig. 4.4: Professional Significance in the Construction Phase ................................54

Fig. 4.5: Recommendations for Additional Education ........................................56

Fig. 4.6: Lawsuits of Today vs. 30 Years Ago ...................................................57

Fig. 4.7: Errors \& Omissions and the Architect's Liability ...................................59

Fig. 4.8: Level of Errors and Omissions in Construction Documents .....................60

Fig. 4.9: Level of Errors and Omissions with a Construction Manager ..................61

Fig. 4.10: Collaboration of the General Contractor and the Architect.....................63

Fig. 4.11: Construction Manager Impact on the Architect ...................................64

Fig. 4.12: Involvement of the Construction Manager in the Design Phase ..............66

Fig. 4.13: Design-Build and the Lead Professional ..............................................69 


\section{CHAPTER 1 \\ INTRODUCTION}

\section{Background of the Problem}

For centuries the architect was the keystone of every large construction project. The architect, throughout history, has been a master builder who held responsibility for both the design and the construction of a building. In fact, the term architect was derived from ancient Greece where Arkhi meant head chief or master and tekton meant worker or builder (Berman, 2003). Today, however, the role of the architect has evolved into a profession that is unique from the historical definition. Specialization has separated the design from the construction and has introduced new professionals and methods to the construction process. The role of the architect has shifted and needs to be clearly defined today.

During the nineteenth century, construction projects began to grow in complexity and scale. Growth led to new technology and techniques. New technology and techniques then led to specialization. Steel beams for multi-story buildings, elevators, plumbing, ventilation systems, central heating, and electric lighting all began to be incorporated into the construction projects of the period. The master builder could no longer maintain its level of expertise in all the trades and aspects of the building process. Sub-contracts began to be written between the builder, or general contract holder, and the individual trade experts. As a result, the apprentice-trained master builder began to lose his expertise 
in all the building disciplines. Without this expertise, he struggled to successfully integrate all the trades into a constructible and efficient design. America was in need of educated/full-time architects and engineers to regulate the industry and ensure proper construction. The result of this was that the master builder separated into two distinct professionals; the designer and the builder (Thomsen, 2002). This separation was the first step in the industry fragmentation that we see today.

Complexity and size of projects continued to grow into the $20^{\text {th }}$ century. Projects such as the Empire State Building, in the 1930's, drew upon a very large number of skilled professionals. The activities of the architect, structural and mechanical engineers, construction companies, material suppliers, as well as many others all had to be coordinated in ways both precise and all-encompassing. Many decisions, which could have a major impact on the entire outcome of the project, had to be made (Kostoff, 2000).

Soon after the initial separation of the builder and the designer, the architect began to go through the same process of the builder with his sub-contracts. Consultants to the architect began to assume the responsibility of various areas of specialization, such as electrical design, mechanical and plumbing design, and structural integrity. Today, the architect will even engage additional architects as specialized consultants, such as landscape, interior, acoustical, and laboratory designers (Woods, 1999). As projects became more complex, errors and omissions, on the part of the design team became more prevalent. And with a growing number of professionals involved on the project, it became easier to place blame on others.

As we progress into the twenty-first century, new technology continues to be revealed. As the new technology or construction techniques are revealed, more experts or 
specialists will be required. Fragmentation of the industry, as history has proven, follows specialization (Thomsen, 1999). It is not uncommon today to have an architect with 1520 consultants, a general contractor with 40-60 subcontractors, and subcontractors who deal with hundreds of manufacturers and suppliers.

To counteract the confusion of the fragmentation, there have been new professionals, such as the construction manager, introduced and alternative delivery methods attempted. Each new professional and delivery system effects the definitions and roles of all those who are involved which leads to confusion of roles and a lack of communication among the professionals responsible for the success of the project (Berman, 2002).

Christopher Widener (2000) spoke at the annual AIA conference regarding the next generation of architects. He feels that the architect is still the principal agent for the construction process and will be able to eventually reinstate the master builder concept to reduce litigation and simplify the source of responsibility. A survey of architecture, engineering, and construction professionals from the San Francisco Bay Area in California, however, suggested that designers are typically inadequate in performing construction management services and do not have a high enough knowledge of construction techniques to control the entire process (Yates, 2003). According to Steve Ehninger, AIA, Builders feel that the architect, in an attempt to avoid liability, has focused too much on just the aesthetic design and has become too specialized to manage the project from inception to completion. 


\section{Statement of the Problem}

The main problem is that the profession of the architect is in its infancy and is still trying to find its place in a continuously evolving construction process. While the term architect came into use during antiquity, the profession of the architect, as it is understood today, was not created until the nineteenth century (Briggs, 1974) (Kostoff, 2000). The master builder of the past no longer exists. It has been fragmented through specialization which has eliminated a single source of responsibility and hindered collaboration due to the growing number of professionals involved. To counteract, the construction industry has been exploring alternative delivery methods and the introduction of new professionals such as the construction manager. Although these attempts have resolved some concerns, they have also introduced new problems such as confusion of definitions and conflicts of roles. This evolution of the construction industry has left the architect of today without a clear definition or position.

Question: What exactly is the position of the architect in the construction process today and what will be its role in the future? The position of the architect has shifted today and needs to be re-defined. The addition of new professionals, such as the construction manager, and alternative delivery methods, such as design-build, are redefining the roles of all those professionals who are involved. The architect will never lose the role of the designer, but it appears that it may cede some of its traditional responsibilities of pre-design scheduling and budgeting, and post-design administration to the construction manager. Conversely, it is possible that the architect, in the future, could 
recapture its role as the master builder or explore alternative responsibilities and define new tasks that will support the owner in building a successful project.

Rationale: The master builder concept originated with the architect who originally held the responsibility for both the design and the construction. Furthermore, the role of the architect has been modified and shifted throughout time, yet historically, it has managed to be the focal point of the construction process. Conversely, the construction manager is very young, originating in the 1960's. While it is young, it has been, and will continue to be, a great asset to the construction process. Nevertheless, the architect still holds too high of a responsibility and has been too resilient throughout history to have its role completely consumed by the construction manager.

In addition, projects of today are becoming too complex, lawsuits more prevalent, and role conflicts more frequent. The industry is looking to reverse the fragmentation that has sparked these problems and are desirous to have a single point of contact and responsibility once again.

\section{Purpose of the Research}

The purpose of the research will be to identify the factors that have caused the role of the architect to change. And through an analysis of these factors, gain insight into the direction of the architect's position in the near future. 


\section{Research Objectives}

The objective of the research will be to identify the following:

1. The role of the architect and how it has changed throughout history.

2. The current role/definition of the architect.

3. The current level of involvement of the architect in the construction process.

4. The factors that impact the role of the architect.

5. Indications into the future of the role of the architect.

The research will be conducted through the Delphi method. The use of this method will provide the most current data regarding the position of the architect. It will also, based on the current standings, provide a greater insight into new trends that are appearing that will have an impact on future developments of the architect and the construction industry.

\section{Assumptions}

- The current definition of the architect has changed from the historical definition.

- Traditional responsibilities of the architect are defined by the design-bid-build delivery method.

\section{Delimitations}

- The research will only address commercial construction and shall not consider highway, industrial, or residential construction.

- The Delphi procedure will focus on, but not be completely limited to, professionals and trends in the state of Utah. 


\section{Definitions}

Architect: The person lawfully licensed to practice architecture or an entity lawfully practicing architecture.

Architecture: The art and science of designing and erecting buildings.

Builder: One that builds; especially one that contracts to build and supervises building operations.

Construction Manager: A professional service that applies effective management techniques to the planning, design, and construction of a project from inception through completion for the purpose of controlling time, cost, and quality.

General Contractor: The person or entity holding the prime contract in a construction project. Or, the definition of today implicates the responsible party for all facets of the actual construction.

Sub-Contractor: Trade specialists such as electricians, plumbers, HVAC technicians, etc. that are retained by the general contractor to install portions of a residential or commercial building.

Master Builder: A full service team, or individual that performs all facets of the construction process including design, engineering and construction. 
Design-Bid-Build: Delivery process in which the owner hires an architect based on qualifications to create the construction documents and a builder based on lowest bid to complete the construction.

Design-Build: Delivery process in which one entity performs both architecture/engineering and construction under one single contract.

Construction Management at Risk: Delivery process in which the contractor is selected based on qualifications and is contracted at the same time as the $\mathrm{AE}$ team. The contractor then acts as a consultant for the owner during the design phase for items such as scheduling, cost estimating, value engineering, and cost flow projecting.

Contract Administration: The management of all actions, on behalf of the owner, to assure compliance with the contract and construction documents. 


\section{CHAPTER 2}

\section{REVIEW OF LITERATURE}

"Past cultures have helped shaped the architecture and construction of today (Miller, 2003)." Accordingly, a study of the history of the profession is essential in gaining insight into the environment of today. While the roots of the architect can be traced back to the world's first edifice, it has only been recognized as a professional in the past 150 years.

\section{Ancient History of the Architect}

Ancient Greece and the Origins. The roots of the architect can be traced back to the times of the Ancient Greeks. The term architect, or arkhitekton in Greek, was the title given to the master builder who would oversee the design and construction of each construction project. A literal translation of the term shows that arkhi, in Greek, means head chief or master while tekton means worker or builder (Berman, 2003). The master builder was typically the head carpenter or head mason on the project, depending on the primary material used for construction. The head builder would assume the responsibility of the design and would work out all construction details throughout the construction process. While the Greek landmarks that are seen today are built of stone, the majority of construction was actually wood. Because of this, it was the master carpenter who became the first architect, or arkhitekton (Woods, 1999) 
Prior to 500 B.C., there were virtually no structures that existed above the ground floor. Building construction was basic and did not require a high level of expertise (Swaan, 1977). The Greek civilization changed this pattern and provided revolutionary changes in building and architecture. The Greek's introduced a stationary dominance that brought an end to nomadic life which began the construction of permanent entities. Furthermore, Greek culture was highly influenced by a belief in religion. As such, a number of their buildings were designed toward this belief. Some of the temples created by the Greeks are still landmarks and are highly influential in modern architecture (Miller, 2003).

Ancient Rome and the Architect. The architecture of Ancient Rome has had a lasting impact on civilizations that have followed. Residents of Rome enjoyed a lavish lifestyle of luxury, art, trade, power, and entertainment. The great icons of the civilization such as the Coliseum, fountains, aqueducts, roads, and the forum reflect their culture and stand as landmarks of their history (Miller, 2003). The scale and complexity of these icons have intrigued historians for years. How could they have designed and engineered such projects in ancient times? The plumbing system of the period, for example, was revolutionary and the first of its kind. The aqueducts would bring water from the coast to provide fountains, running water, pools, baths, and sewer systems. The master masons alone could not have had the expertise to make this system work so well. The new levels of complexity triggered a shift in the role of the architect toward individuals with different backgrounds. Prominent architects of the period came from military engineers, 
civil servants, or even private training (Woods, 1999). The architects would develop a design and plan and then work together with the master builder to carry it out.

Europe and the Dark Ages. As the Roman Empire fell, and the world entered the Middle Ages and Dark Ages, the term "architect" was rarely used. Innovation and new ideas were replaced by a simple drive to exist. The culture of this era was one of fortification and defense (Miller, 2003). Elaborate designs and intricate details lost priority to the tall stone walls and castle fortresses. The master mason and carpenters once again held sufficient knowledge to construct the buildings and did not require any special design or engineering expertise. Master builders and master masons, whose identities are now largely lost, were the designers and the creators (Woods, 1999).

Emergence from the Dark Ages - The Renaissance. As the wars of the Dark Ages ended, city walls and barricades were slowly eliminated and civilization went through a re-birth, or Renaissance (Miller, 2003). An aspiring architect of the thirteenth century would serve an apprenticeship as a cementer and stone cutter. Once a master mason, he would be considered the head builder. As the head builder, he was also the one who would ultimately define the design of an edifice (Miller, 2003). Consequently, the architect assumed ultimate responsibility for planning, design, craft management, construction, and a guarantee of usability for the building owner. He was therefore referred to as the "master builder (Coble, 1999)."

Fifteenth Century Europe sought after the beauty and craftsmanship of antique forms creating opportunities for those outside the traditional building crafts of masonry 
and carpentry. The knowledge of antique forms and artwork was possessed by the goldsmiths, sculptors, and painters. Brunelleschi, Michelozzo, Bramante, Raphael, and Michelangelo all received commissions for buildings in the fifteenth and sixteenth centuries. These men were called the architects yet they did not belong to construction guilds and were not masons or stone cutters. It was at this time that the titles of architect and master builder first became separated (Woods, 1999). While some form of an architect had been around since the first edifice was ever built, it was in this period of time that the profession of the architect as a designer, independent from the builder, began to be defined as an integral and mandatory part of the construction process (Coble, 1999).

\section{Modern History of the Architect}

Eighteenth Century America. In colonial and post revolutionary America the title of architect, while quite elastic, still carried the connotations of authority and responsibility similar to the times of the renaissance. However, the first architects of early American settlements were the building artisans. Bricklayers, masons, glaziers, painters, plasterers, and carpenters were all prominent artisans of the century. Yet the abundance of wood made the carpenter the preeminent artisan or the master builder. In turn, the master builder/artisans, who created basic architectural drawings and supervised construction, would be referred to as the architect (Woods, 1999).

In the second half of the eighteenth century, the building artisans began to see competition from a new class of architects. The American elite began to create architectural designs for their own pleasure. They would determine the desired form and 
function, organize the schedule and process, and, occasionally, finance the project. Heavy reliance was then placed on the craftsmen and artisans to execute their designs and work out the constructability issues. This group of gentlemen, or educated elite individuals, included highly recognized public officials such as: Peter Harrison (1716-1755), Thomas Jefferson (1743-1826), Dr. William Thornton (1759-1828), and Charles Bulfinch (17641844). Rarely would these gentlemen accept payment for their designs. Therefore, the competition with the building artisans was not financially driven; it was a competition for the title of architect as laws did not restrict the use of the title (Woods, 1999).

Nineteenth Century - Establishment and Development of the Architect. The early 1800 's experienced new heights in construction technology. Steel beams for multi-story buildings, elevators, plumbing, ventilation systems, central heating, and electric lighting all began to be incorporated into the new construction. The apprentice-trained craftsmen struggled to maintain their expertise in all aspects of the process. America was in need of educated/full-time architects and engineers to regulate the industry and ensure proper construction (Landau, 1996).

Culturally, legally, functionally, and economically, the design of buildings first began to separate from the construction. The architect worked out the design and construction details and then attempt to describe it to the builder through drawings. "The $\mathrm{AE}$ was the master of building technology - the brains. The builder was the brawn (Thomsen, 1999).”

The architectural office saw many changes throughout the nineteenth century. Initially the office would consist of one, perhaps two, architects who would work alone as 
an artist in developing his design. A problem soon arose with this scenario: few architectural offices survived the retirement or death of the principals (Woods, 1999).

Throughout the nineteenth century the architect evolved from a single individual to ateliers with pupils, to partnerships, and finally to large offices. The large office was an established fact by the end of the nineteenth century which allowed the firms to live beyond the lives of the founding principals. Well-known of the first of the large offices was D. H. Burnham, founded in Chicago in 1873. The Chicago building boom of the 1890's brought about many opportunities. Daniel Burnham capitalized on this and hired professionals with skills that he lacked. He once said; "My idea is to work up to a big business, to handle big things, deal with big businessmen, and to build a big organization (Kostoff, 2000)." By the turn of the century, D. H. Burnham had grown to 180 employees with branch offices in New York and San Francisco.

Nineteenth Century - Professionalism. The status of a "professional" is one that was held for educated gentlemen of early America. The term "profession", in sixteenth century English usage, first meant a vow or oath taken upon entering a religious order. By the mid eighteenth century it had been expanded to include anyone entering a "calling" or an occupation - primarily divinity, law, and medicine (Gordon, 2004). The title of profession became a symbol of dignity linked with "university education, gentlemanly social status, some degree of leisure and discretion, and exemplary character (Kimball, 1992)." As others outside of the realm of divinity, law, and medicine desired this status, a profession of the nineteenth century came to be known as "an occupation that regulates itself through systematic, required training and collegial discipline; that has 
a cognitive base in specialized technical knowledge; and that supposedly has an

orientation of service to clients and the public good, embodied in a code of ethics (Starr, 1982)."

The idea of an architect as a professional in the early 1800's was a new concept.

As such, it was ill-defined and unorganized (Briggs, 1974). Kostoff (2000) described the status of the profession of architect in the early 1800's as follows:

In public estimation the architect continued to occupy an uneasy position halfway between the unscrupulous contractor and the feckless artist. The profession of architecture as it is understood today was created in the $19^{\text {th }}$ century, in imitation of medicine and the law, then as now the dominant professional occupations. The ideals of the traditional architect were the ideals of society; like the older professions it imitated, the new profession of architecture replaced the ideals of society with the ideals of the profession itself. For the ideals of the profession, the modern architectural office in its turn substituted service to the firm, as in other modern businesses.

An attempt to organize the profession of architect led to the establishment of the American Institute of Architects (AIA). Founded in 1857, this organization began to define laws and standards for the profession. It both formed and informed the architects of the nineteenth century. The principal goal of the AIA was "the establishment and maintenance of a perfect understanding as to prices and methods of conducting business (Woods, 1999)."

Nineteenth Century - Education. Formal education of the architect first appeared in Europe with the establishment of the first school of architecture in Paris in 1819. "Not before the return from Europe of the first Americans, who had studied at the Ecole des Beaux-Arts in Paris, did the older methods of training begin to be replaced, and architects begin to organize themselves into a professional body (Kostoff, 2000)." The school of 
architecture, in Paris, taught students through ateliers, or design workshops. This method triggered collaboration and fostered new ideas. The first Paris trained American architect to establish an atelier focused office was R.M. Hunt. Prior to this, architects worked alone. With more architects graduating from the school in Paris more offices began to be organized in the same manner. Those unable to attend school in Paris would work in established offices as pupils or junior employees and be able to initially gain their education by working and learning from those already in practice (Kostoff, 2000). The first American school of architecture was established at the Massachusetts Institute of Technology (MIT).

Twentieth Century America - Business Practices. J. F. Harder (1902) stated "the architectural opportunities fall to those who are preeminent for business rather than artistic ability, and thus, it is they who build the architecture of the country, good, bad or indifferent. The architect must be a business man first and an artist afterwards." Outside the profession, people still regarded the architect as an individual artist/practitioner. Yet, within the profession, the change in methods of practice was very noticeable. Running a firm as a business was crucial to success. In addressing the criticism of shifting from an artist to a businessmen, a prominent architect from New Jersey, in 1914, stated "instead of our successful architects as a whole constituting a class of befogged dreamers they are in reality fully as keen and of as large capacity in the business of money getting as any other constituency in American affairs (Kostoff, 2000)." 
Twentieth Century - Coping with Growth. Organizations of the twentieth century soon had to respond to the demands of increased project size and work complexity. In the 1930's very large numbers of skilled professionals, drawn from various fields, were needed for projects such as the Empire State Building and the Rockefeller Center. The activities of the architect, structural and mechanical engineers, construction companies, material suppliers, as well as many others all had to be coordinated in ways both precise and all-encompassing. Many decisions, which could have a major impact on the entire outcome of the project, had to be made. The decision-making responsibility became overwhelming and had to be separated from the labor. This unavoidable result of the demands of the work soon became a basic principle of organization in the architect's office. A special level of employee was created between the principal and the other employees. The sole task of this employee was to supervise the work process itself; a function unrelated to any traditional or modern skill (Kostoff, 2000). In addition to the separation of decision-making, large buildings also led to a separation of various aspects and stages of the design. Certain designers and workers would specialize in various aspects and focus completely on that aspect. This separation of roles within the office paralleled, to some extent, the specialization of practice in general. Offices became known for their area of expertise - religious buildings, hospitals, schools, office buildings, etc. (Woods, 1999). By the 1950's the pattern of organization found in the large offices had come to be very widely followed in American practice (Kostoff, 2000).

Twentieth Century - Organizational Structure of the Office. The office of Skidmore, Owings, and Merrill brought another revolutionary change to the architectural 
practice. They set out to provide every kind of professional service within a single frame: design, structural engineering, production services, interior design, graphics, mechanical and other engineering specialties. The goal of the organization was to gain success and recognition. The mean was to have national coverage and dominate through volume. The method was patterned after the master builder of the middle ages who worked very efficiently. The partners of the firm pledged "to offer a multi-disciplined service competent to design and build the multiplicity of shelters needed for man's habitat (Landau, 1996)." The firm was originally founded in 1936 by two architects; Louis Skidmore and Nathaniel A. Owings. In 1939 they were joined by John O. Merrill, an engineer. By 1958 the firm consisted of 14 general partners, 15 associate partners, 39 participating associates, more than 1,000 employees, and offices nationwide. The division of the practice into separate offices provided an unprecedented diversification which allowed it to stay profitable when some offices were slow. Although it never became incorporated as a business, its style of organization and operation was essentially that of any corporation (Landau, 1996).

Other offices followed this pattern and began to focus on mass production and profitability in order to survive and maintain themselves, just like any business. In 1950, the AIA conducted a survey of professionals. In this survey the AIA found that, at the time, there were 19,000 registered architects and 90,000 unregistered professional employees in architectural offices. With the addition of associated professionals and nonprofessional workers, the total of those engaged in all architectural professional activities was just over 140,000. It further found that about one half of all registered architects worked in firm of four people or less (Kostoff, 2000). 
Toward the end of the twentieth century, it became obvious that the architects in modern America indeed came to terms with the facts of the evolving industry and commerce. "Ethics of individual architects were replaced by ethics of the office, and the more the architect's office resembled business in general, the more did its ethics resemble those of the business world (Kostoff, 2000). Treating architecture as a business was somewhat destructive of its own self-image; particularly for those individuals who entered the profession with high ideals.

Into the Twenty First Century. As the architect entered the twenty first century, his skills were still exercised in design, "but even more would he or she possess a capacity for coordination, compromise and negotiation, the ability to balance competing demands and needs, and to appreciate the points of view of other professionals with their own desires (Woods, 1999)".

\section{The Builder in American History}

The construction industry was formally organized in the United States in 1724 by the Carpenters Company in Philadelphia. Shortly, other organizations followed in Boston and New York. These organizations were considered to be "master builders." Master builders were responsible for the design, survey, engineering, and management of the construction. In other words, he would be the architect, engineer, and superintendent for each project (Yates, 2003). As the architect separated out and became a distinct

professional, the builder became the constructor. During this same period, projects also began to grow in complexity and trades became more specialized. It soon became too 
expensive for the builder to train the laborers in all of the fields and to maintain the equipment and tools necessary to effectively perform all the trades. Sub-contracts began to be written between the builder, or general contract holder, and the individual trade experts. Thus the builder became known as the general contractor, the one holding the prime agreement with the owner (Thomsen, 2002).

\section{The Construction Manager in American History}

There is little that has been published to document the exact origination of the construction manager. This may be accredited to the lack of an exact definition for quite a period of time. The most widely accepted definition, today, is: “A professional service that applies effective construction management techniques to the planning, design, and construction of a project from inception through completion for the purpose of controlling time, cost, and quality (www.cmaa.org, 2005)." Based on this definition, it has been accepted that the construction manager first emerged via the nation's largest general contractors in the early 1960's. Tishman Realty \& Construction Co., Inc. (TR\&C) has generally been acknowledged as the pioneer of construction management. TR\&C claims to have devised the service and first implemented it on the construction of Madison Square Garden in New York City in 1963. The project was successful so TR\&C implemented the service again on the John Hancock Center in Chicago in 1965 and then the World Trade Center twin towers in 1967 (Berman, 2002). According to TR\&C, the inspiration for this service "was the growing owner's need for accurate and knowledgeable guidance throughout the entire life cycle of a project due to the increasing size and technical complexity of projects (Berman, 2002)." 
The General Services Administration (GSA) petitioned a study of construction processes to determine which delivery method was the best one in reducing construction times and costs. The result of the study was that the best method was a "phased construction in conjunction with construction management services (General Services Adminstration, 1975)." From this study, contracting and consulting firms began to explore alternative methods and refine the construction management process. The result of this was the establishment of the Construction Management Association of America (CMAA). The association was founded during a two day conference in Denver, CO in April 1982 (www.cmaa.org).

CMAA is a young organization. The goal, however, is to professionalize the industry in a similar manner of the AIA. In 2002, the state of Idaho took the first step in helping CMAA meet this goal. The following is an excerpt from Idaho Statute 54,

\section{Chapter 45:}

Except as otherwise provided herein, on and after the effective date of this chapter, it shall be unlawful for any person to act as a construction manager in public works construction or to practice or perform or offer to perform construction management services in public works construction unless such construction management services are performed by or under the direct supervision of a licensed construction manager (Idaho Statute Statues, 2005)).

To qualify as a licensed construction manager, in Idaho, one must successfully complete the CMAA application and examination process and be registered with the CMAA (Idaho Statute). Currently, Idaho is the only state that requires a construction manager to be licensed. 


\section{Legal History}

As the architect continued to grow as a professional, laws began to be enacted addressing his operations. The first state to pass a licensing law for architects was Illinois in 1897. The U.S. government began to recognize the professionalism of the architects and engineers by passing a law in 1903 that required government organizations to hire professional architect consulting services instead of using government employees for architectural services. Then, in 1972, the Brooks Bill (Public Law 92-582) was enacted. This bill further required government organizations to hire professional architects based on qualifications, not low bid (Oualline, 2004).

Due to the uniqueness of each construction project, mistakes and deficiencies do occur occasionally. The client has a right to expect a defect-free building from the builder. As the architect became a professional separate from the construction, however, the U.S. courts ruled that an architect's performance would be judged on professional judgment, not craft. This meant that errors could be tolerated and the architects, to defend themselves, would only have to prove that they had acted with an "overall professional standard of skill, knowledge and judgment (Sapers, 1984)." Therefore, if a mistake is made by the architect, within the "overall professional standard", and the builder builds the mistake, the client has to pay for the correction. Today, this is typically addressed as a change order that can become very costly to the owner (Thomsen, 1999).

\section{Current Roles in the Construction Process}

The construction process of today has become very complex. The number of individuals involved on the project can easily number into the hundreds. It becomes a 
challenge to know where exactly the responsibility and the expertise reside. Fig. 2.1 illustrates the typical organization and level of involvement on a construction process today.

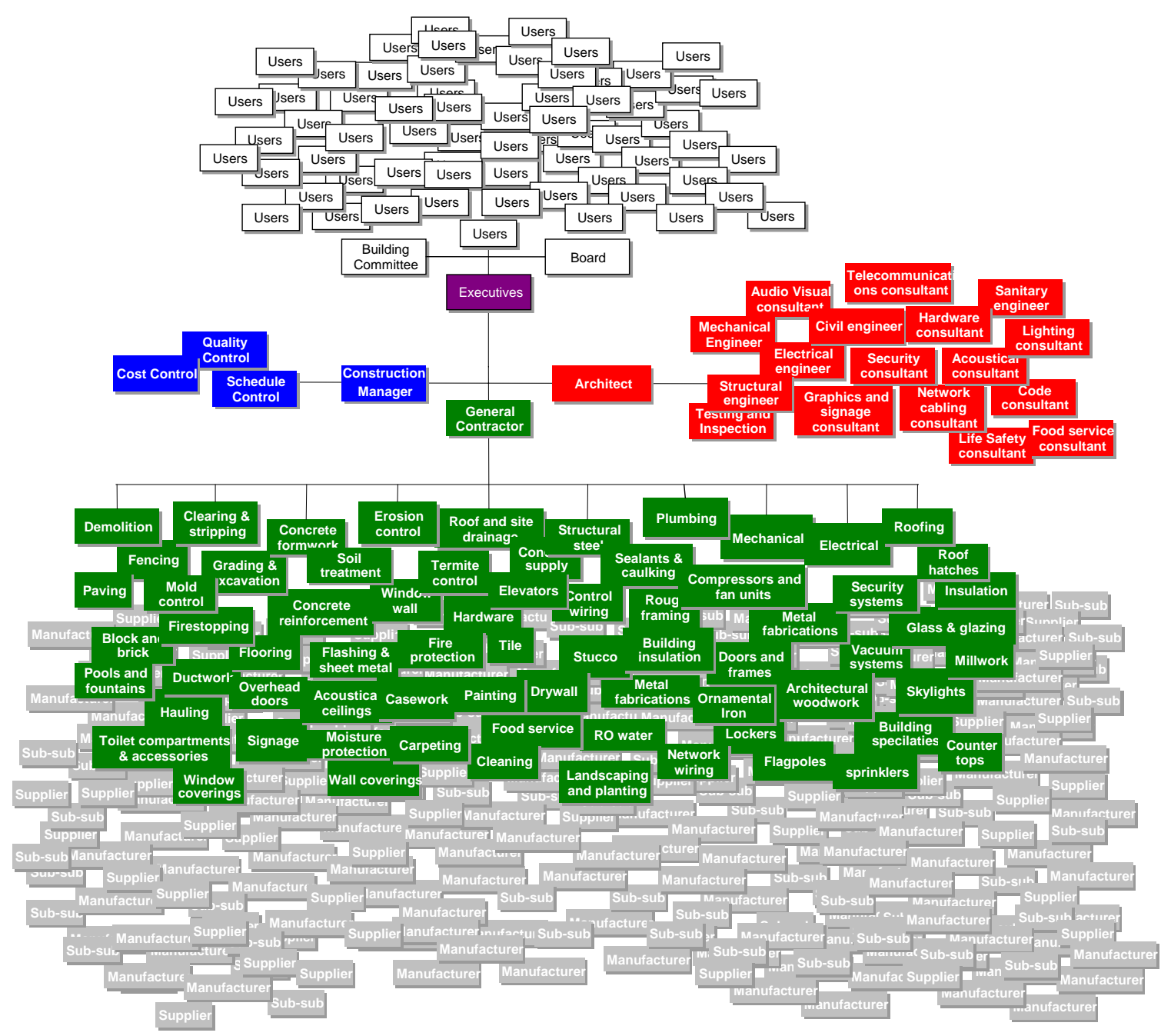

Fig. 2.1 - Construction Project Organizational Chart

The Architect of Today. The architect is no longer the construction technology expert. That knowledge is now reserved for the manufacturers, suppliers, and specialty consultants. The architect today is not a master builder; he is a manager and systems 
integrator. The duties of an architect today, in the design-bid-build method, begin with conceptual design and continue through the completion of construction. The contract documents will break up the architect's role into five phases:

1. Schematic Design - Preliminary design concepts are realized as the architect meets with the owner to discuss their needs and budget.

2. Design Development - Once the owner approves a design concept, the architect forms the design drawings, a construction budget, and a schedule.

3. Construction Documents - The architect develops the design drawings into detailed documents and specifications from which the contractor will base its bids and construct the building.

4. Bidding or Negotiation - The architect assists the owner in soliciting bids for the project and answers all questions that the bidding contractors may have.

5. Construction - The architect conducts site inspections on behalf of the owner to ensure that the project is being built according to design, answers requests for information from the contractor, review submittals, collaborates to solve design and construction issues, generates the punch-list for the contractor and issues substantial and final completion (Duff, 1999

The AE team acts as an agent to the owner who is striving to protect the owner. Furthermore, the architect is hired based on qualifications. Therefore, the architect is constantly striving to work in the best interest of the owner. (Thomsen, 2002). 
The Construction Manager of Today. The construction manager (CM) is a management tool and should be nothing more. The role of the CM is to "apply management techniques to the planning, design, and construction of a project for the purpose of controlling time, cost, and quality (Berman, 2003)." It should be considered as an extension of the owner's staff. "They should not prepare any design documents, purchase any of the materials/ equipment, or construct any of the work (Berman, 2003).” In doing this, the interests of the construction manager remain the same as those of the owner - the construction manager should not be conducting any services that promote his own personal interests.

\section{Role Conflicts}

The traditional method is based on the flawed assumption that architects can prepare flawless plans and specifications. However, architects do make mistakes and when they do, everyone suffers with the claims. Legal costs add to the budget and destroy profits for the architects and the builders. To protect themselves, the clients have begun to add additional layers of consultants. These consultants include the construction manager, program manager, and construction quality manager (Thomsen, 2002).

Historically, architects have conducted the contract administration on projects. That is, they will remain on the project after the design is complete to represent the owner and ensure that the project is built as specified, on time and under budget. They have also been the owner's consultant in the pre-construction to inform the owner of budget and scheduling issues. The emergence and popularity growth of the owner's additional 
consultants, however, is currently causing a conflict or power struggle between the professionals.

Construction is an industry that is litigious by nature. Unfortunately it is full of distrust, unethical practices, stereotypes, disputes and claims. The reputation and numbers of lawsuits/litigations have created pessimistic owners who try everything they can to have their project meet the three primary objectives of time, cost and quality. Anytime one of the objectives is not met, the owner will question his decisions, trust, and the credentials of the professionals who have been engaged. So with all the precautions and pessimism, why is there still so much litigation and problems in the industry? The additional experts that are hired by the owner, for the benefit of the owner, often intrude into the field of expertise of the other professionals already involved on the project. This entrance will trigger conflicts. Often times it is difficult to recognize the conflicts, otherwise, the situation would be altogether avoided. As more professionals become involved in the project, however, it becomes harder to sort out the roles and responsibilities. According to Berman (2003), "a prime problem in the industry stems from the ambiguity over who owns and who is ultimately responsible for managing the design and construction phase of a project."

In the construction process, there are typically two professionals that struggle more with role conflict than any other parties. That is the architect and the construction manager. "It is imperative that the scope of services for the architect and construction manager be clearly defined and that services be delegated to the entity best qualified to provide them (Berman, 2003)." 


\section{Legal Disputes}

Just recently an architect, Christopher Kourafas, was hired by Basic Foods, Inc. to perform the design of a facility in Las Vegas. Upon completion of the design, a second agreement was executed for Kourafas to manage the construction of the facility. Payment was made for the design portion of the work, but upon completion of the construction Basic Foods refused to pay for the construction management services. As Kourafas sued for breach of contract, Basic Food moved for a motion to dismiss based on the argument that "Kourafas was not a licensed contractor and, therefore, could not assert a claim for payment of construction management services (Caplicki, 2005)." The trial court agreed with Basic Food and dismissed the lawsuit. The appeal court then ruled that "simply because the definition of a contractor includes a construction manger, does not mean an architect cannot perform construction management services...[and] the practice of architecture does not end at only preparing plans and specifications. Thus, an architect can, if the contract so provides, continue to assist in any phase of construction pursuant to his licensure (Caplicki, 2005).” However, the appeals court still could not make a ruling. Due to the lack of facts, they could not determine if Kourafas exceeded the scope of his license. The case has now returned to the trial court and is awaiting a verdict.

The state needs to make it very clear as to what activities a construction manager needs a contractor's license, and to what extent architects and engineers may perform such services. If this is not clearly defined by the state, the responsibility falls on the owner to identify, in their contracts, the scope of each professional. Until this is done, there will be confusion over role responsibilities that will trigger conflicts and fingerpointing. 


\section{Contract Agreements}

To define the roles of the architect and construction manager, one must refer to the contract that was formed. Many sophisticated owners or professionals will draft their own contract forms. If the owner does choose to do this, he must specifically define the roles and responsibilities of each professional that will be involved. Yet the majority will use standard forms that have already been created. AIA, CMAA and AGC have all created standard forms that separate and define the roles and responsibilities of the architect and the construction manager. AIA, for example, has the A201 standard form agreement for the Owner-Architect and another agreement for the Owner-Construction Manager (AIA). It is not recommended to use an AIA form agreement for the architect and an AGC or CMAA agreement form for the construction manager. This may result in conflicting definitions.

\section{Construction Expertise of the Architect}

The mindset in the industry today seems to be that architects no longer have the construction knowledge necessary to manage large scale projects. The decline in construction knowledge may be attributed to: industry fragmentation, lack of formal construction education and minimal training or hands-on experience (Yates, 2003).

Education. To practice architecture, one must receive a Master's degree from a university approved by the National Architecture Accrediting Board, participate in the IDP (intern development program), and then sit for the Architect Registration Exam. The Master's degree requires a course in basic construction materials and methods and a 
couple of structures courses. It does not, however, require any management courses or hands-on construction experience (www.aia.org).

The practice of construction management does not require any formal education or training. However, job postings will typically require a bachelor degree in construction management or civil engineering.

Training. A survey of formal and on-the-job training was conducted of San Francisco area professionals. The professionals that responded to the survey are separated as follows:

\section{Table 2.1: Survey Respondents}

\begin{tabular}{lc} 
Type of professional & $\begin{array}{c}\text { Percentage } \\
\text { of } \\
\text { respondents }\end{array}$ \\
\hline Contractors and sub-contractors & 25.9 \\
\hline Construction managers & 4.5 \\
\hline Designers from architectural firms & 34.8 \\
\hline Designers from engineering firms & 19.1 \\
\hline Designers from multidiscipline firms & 6.7 \\
\hline Property managers and owners & 7.9 \\
\hline Other types of firms & 1.1 \\
\hline
\end{tabular}

$74 \%$ of the respondents do not have formal training programs at work. $40 \%$ do not have on-the-job training. $36 \%$ do not have either formal or on-the-job training. Only $23.4 \%$ receive both formal and on-the-job training at work (Yates, 2003).

The background of the profession is expected to be acquired in the colleges and universities while practical knowledge is expected to be learned on the job. The majority of the respondents felt that their firms did not provide enough training. The firms, on the 
other hand, cannot always afford to provide more training. They are concerned that if they invest the money to train individuals, those individuals will no stay with the firm long enough to recoup the costs (Yates, 2003).

\section{Industry Perception of the Architect}

The survey mentioned above also inquired as to the amount of expertise that is thought to be required in the industry. $66 \%$ of the respondents thought that designers should have construction field experience prior to starting a design career. $76 \%$ thought that construction field experience should be required prior to receiving professional registration. In fact, $67 \%$ recommend a minimum of 1 to 3 years field experience. Only $3.6 \%$ thought that construction field experience was not necessary. Furthermore, $91 \%$ believe that construction methods, processes, and management ought to be part of the designer's formal education. And 79\% believe that the amount of errors and omissions claims against a designer would be reduced with a higher level of field experience (Yates, 2003).

Through the survey results, the author concludes that designers are typically inadequate in performing construction management services.

\section{Fragmentation and Specialization}

In the year 1889, the first electric elevator was installed in the U.S. This is a very significant event in the history of construction and architecture. This was one of many new construction technologies that made it too difficult for apprentice-trained craftsmen to maintain its expertise in all facets of the construction process. Specialization had 
begun. Educated and qualified architects and engineers became necessary to ensure a solid product (Thomsen, 2002).

Today, contractors, engineers and architects are becoming even more specialized. Specialization brings expertise in a certain area. But it also brings further fragmentation of the master builder theory and lack of knowledge in other areas.

Constructability input is hindered by the partial understanding of construction requirements by designers, the fragmented delivery process, contracting practices, diverging goals between design and construction professionals, and changes in construction methods and materials (Yates, 2003).

\section{Delivery Methods and the Role of the Architect}

Design-Bid-Build. In modern American history, 8 out of 10 construction projects have been delivered through this method. In this process, the owner will determine his needs/goals, produce an RFQ (request for qualifications) to find the most qualified architect, generate bid documents and select a contractor based on the lowest bid (Tulacz, 2004).

The lack of communication and collaboration between the architect and the builder, during the design phase, is becoming quite a concern with the design-bid-build process. In the mid 1800 the builders experienced an increase in technology that forced them to rely more on specialty contractors. Similarly, architects are experiencing the same issues today. With the amount of specialization required for today's buildings, it is no longer possible for the architect to be an expert in all facets.

Theoretically, the architect is responsible for providing a set of plans that are free from errors and ready to be built. Yet the specialized experts/contractors do not become involved in the process until design is complete and the construction has been awarded to 
the builder. It is very difficult for an architect to provide a set of flawless plans without the input of these experts (Oualline, 2004). Furthermore, the architect is responsible for providing the owner with a cost budget. Yet the construction is awarded based on lowest bid. This makes the pricing somewhat unpredictable. A builder cannot assist the architect with the estimating without running a risk of losing its competitive edge. Errors and omissions in the plans have become so common that the errors and omissions insurance, required for the architect, is now a third to a half of an architect's typical profit (Thomsen, 2002).

Design-Build. Some claim that "The Design-Build method is the easiest way for owners to buy construction (Terry, 2003)." Design-Build has probably been around since the time of Ancient Rome. However, it has only been in the past couple of decades that it has returned. Furthermore, public sectors had no choice but to use the traditional process until House Bill 2340 was amended in 1994 that allowed the use of "alternative delivery methods (Lauer, 2003)." Below is a table that demonstrates the growth of design-build in the past three decades: 
Table 2.2: Design-Build vs. Design-Bid-Build

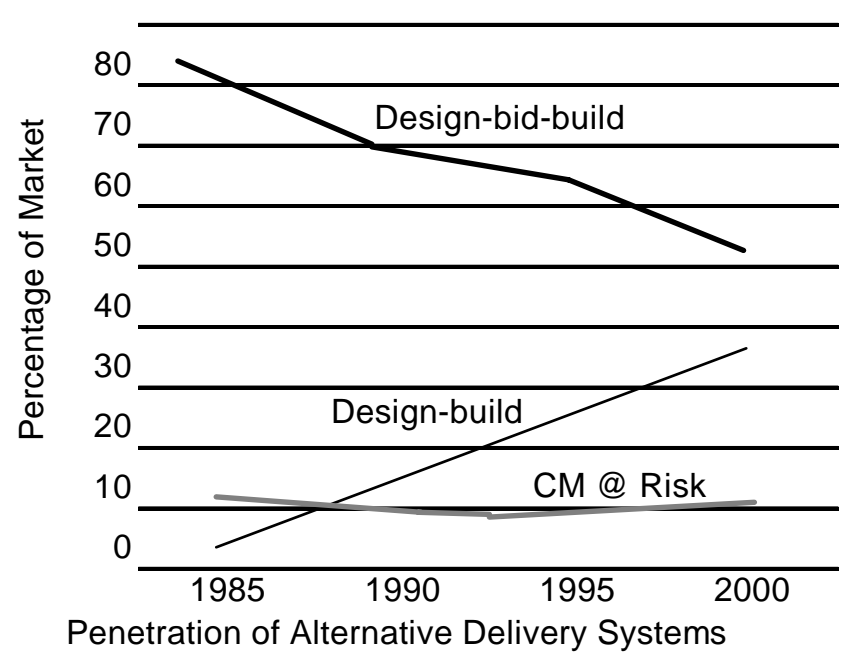

In this process, there will be one team that is chosen at the beginning of the project. This team will remain with the project throughout the duration and will assume responsibility for not only the design of the project, but also for the construction. This team is selected based on qualifications, not lowest bid.

Design-build appears to be the perfect solution to the lack of communication and coordination of the design-bid-build process. Errors and omissions claims are constantly lower in this process. See the following table: 


\section{Table 2.3: Errors and Omissions Claims for Design-Build}

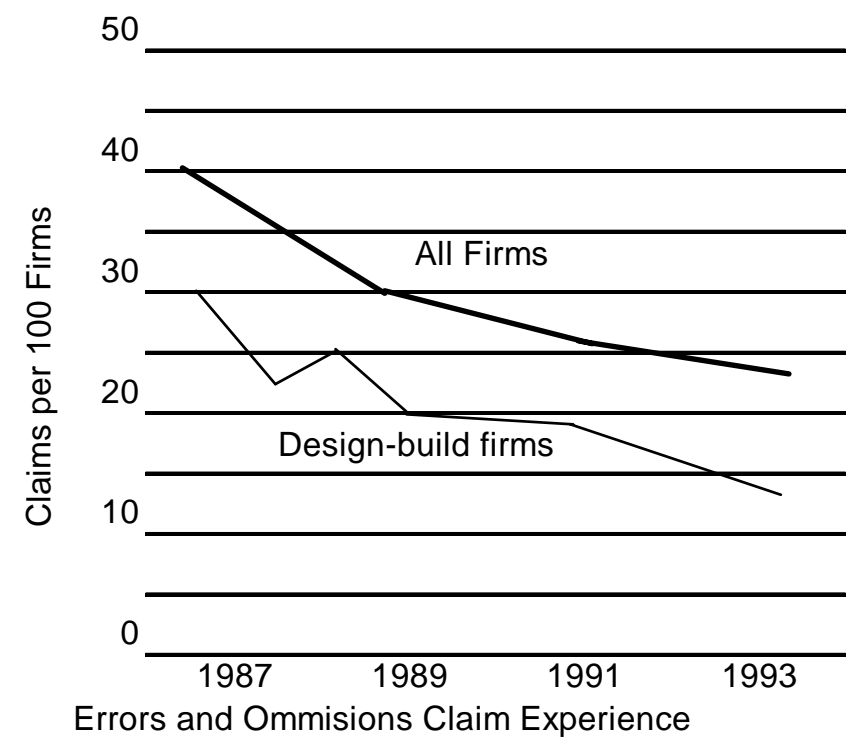

However, it is a difficult task to change the adversarial tendencies of the architect and builder to have them collaborate and work as a team. Furthermore, the builder and the architect simply operate differently. Projects have shown that it is more difficult to find harmony between the differences than it may appear. A few of the differences are: Financial operations, service orientation, and payment methods.

- Financial operations. The architect's income is generated by staff billability and the effective multiplier (revenue received for an employee divided by the employee's salary). The builder, on the other hand, works by a profitability margin - staff driven to optimize income by minimizing costs.

- Service orientation. The relationship between the owner and the architect is paramount. Budgets and schedules become secondary priorities. Many architects will exceed their costs on a project in the hope that future work 
will come from the client. The opposite is true for the builder. Since projects are awarded based on lowest bid, budget and schedule are paramount.

- Payment methods. Overhead for the architect is relatively low. If payment is not received from the owner for a few months, it will likely not cause too much havoc for the architect. Whereas a builder carries a huge direct cost and overhead and is must receive payments as soon as possible to cover their costs.

The integration of the two disciplines requires role changes by both entities. The success of a design-build project is contingent upon the level of teamwork and integration of the two disciplines (Taylor, 2000).

Bridging. Bridging can almost be thought of as a hybrid between design-bidbuild, and design-build. In this delivery method, the owner will solicit the service of an architect as the PM (program manager) at the very beginning of the programming phase. The PM will assist the owner in determining the needs, goals, and at times even the funding of the project. Collaborating with the owner, the PM will then produce contract documents. The complexity and extent of work in the contract documents will vary (this must be arranged in the owner/PM contract). Then, a design-build team is selected to develop the contract documents into construction documents and then will continue to construct the project. The PM will remain as a representative for the owner throughout the entire project to review the construction documents, issue the notice to proceed and generate the punch list (Bridging, 2003). 
The main advantage of this method is the representation of the owner, by a professional, throughout the entire process. This could be very beneficial for owners who are not very experienced in construction. Typically, the PM is also able to deliver a project that has fewer change orders and therefore, a lower overall construction cost (Terry, 2003).

CM at Risk. The owner will administer two separate contracts; one with the AE team, and one with the contractor. However, the difference from this and design-bidbuild is that the contractor will be chosen based on qualifications and will be contracted at the same time as the AE team (Gharehbaghi, 2003). The contractor/construction manager will act as a consultant for the owner during the design phase and will take care of scheduling, cost estimating, value engineering, and cost flow projecting. The term "atrisk" comes from two responsibilities that are assumed by the construction manager. They are: cost risk and performance risk. Cost risk is lumped into what is termed a GMP (Guaranteed Maximum Price). The GMP will be negotiated with the owner early on in the project. Performance risk gives the construction manager the responsibility to turn over a quality project within the given deadline (Tulacz, 2004).

As discussed earlier, however, the use of this method must be pre-qualified with contract agreements that clearly define and separate the roles of all parties involved (Berman, 2003). 


\section{Insights of Tomorrow}

Issues of tomorrow will stem from trends of today. As such, a brief study of current trends should define the direction of the architect in the near future.

Project Definition and Rotation. "The development of the project scope definition package is one of the major tasks in the pre-project planning process (Gibson, 2003)." This is a pre-design phase in which the risks associated with the project are analyzed, early designs are formulated, critical decisions are made and the specific project execution approach is defined (Huovila, 2005). Once the architect has completed the project definition, or programming, the building owner will then take that information and consult another architect to proceed with the design and production of the construction documents. This alone is not a new trend.

Building owners of the today are rarely building just one building. The culture of our society today requires multiple buildings to fulfill the needs of the building owner. College campuses, school districts, government facilities, retail establishments, and healthcare facilities all require multiple buildings and complexes. It could be said that the building owner of today is a "serial builder." This is a shift that is changing the society and industry today.

The project definition, described above, is such a key component to the success of each project. When multiple buildings are commissioned, proper project definition becomes even more critical to the success of the buildings. In an attempt to manage multiple projects, the building owner will become overwhelmed and lose control of each project. It becomes necessary to have a program manager to control all of the projects in 
addition to the project manager of each individual project. Figure 2.5 illustrates the organizational structure when a program manager is involved. Various case studies have found that the implementation of a program manager enables the building owner to "rotate" out certain aspects that are uniform across all projects and move them to a program level. By doing this, the building owner will realize greater efficiencies of cost and time, plus greater control of quality (Thomsen, 2002).

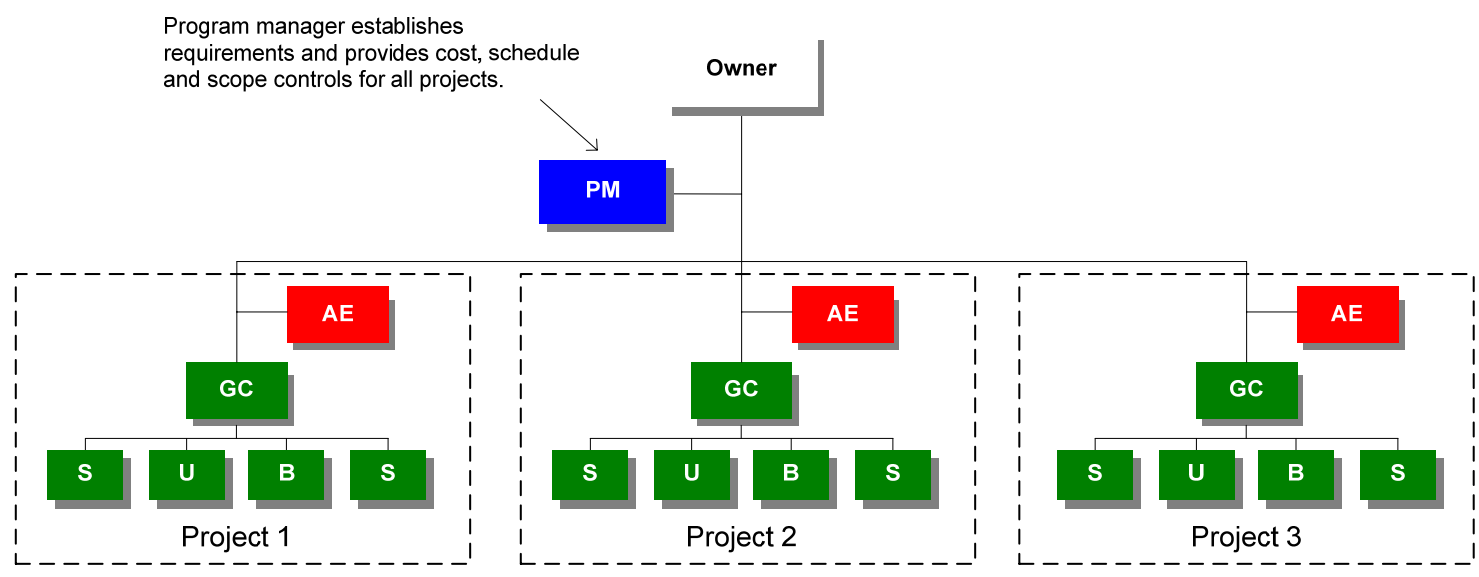

Fig. 2.2 - Position of the Program Manager

A Return to the Master Builder. There is a new trend in the industry that could perhaps be considered as a shift back to the master builder concept. Fast-track and turnkey projects require the integration of many disciplines. On smaller projects, owners often do not have the management skills or staff to separate out the design, engineering, consulting, procuring, and construction contracts. Clients are looking for firms who can provide an all-inclusive service (Taylor, 2000).

This new trend can be beneficial because of the reduced contracts and clear image of responsibility, yet it still can be a struggle for firms to implement. Construction firms 
and design firms have distinct cultures and methods of operations. To have a successful full-service firm, a compromise of the two cultures must take place. Construction involves a large amount of money for procurement, overhead, equipment, and labor. The contract is written and the budget is established for a "defined scope of work and a specific schedule (Taylor, 2000). Design is not as concrete and does not require a large amount of money to operate. Budgets and schedules can easily become a secondary priority to the ideas and changes from the client that can arise. "The key to success in getting different staffs with different backgrounds, corporate cultures, and educations to perform successfully consists in breaking down barriers and misperceptions and showing the value that both groups - engineers and constructors - bring to the project (Taylor, 2000)."

According to Christopher Widener, FAIA (2004), "there is a growing trend for the architect to become the lead on design-build projects." This was stated by Widener as a keynote speaker and was echoed by many seminar participants at the annual AIA convention. As the lead in a design-build contract, the designer (architect) coordinates the project, including the construction, in one of two ways: either as a construction manager for fee or a construction manager at risk. The role of the general contractor is either eliminated or reduced. In the case of a $\mathrm{CM}$ for fee negotiation, the owner must clearly understand that they assume all responsibility for cost overruns, change orders, and late work. In the case of a $\mathrm{CM}$ at risk negotiation, the designer would assume this risk and would charge the client a premium to assume the risk (Odusami, 2002). 


\section{CHAPTER 3}

\section{METHODOLOGY}

\section{The Method}

It is the intent of this research to not only examine the current position, but also to explore future possibilities and indications of the architect's role. It is for this reason that the research was done through a series of Delphi rounds. The Delphi Method is "a structured process for collecting and distilling knowledge from a group of experts by means of a series of questionnaires interspersed with controlled opinion feedback (Adler and Ziglio, 1996)." Wissema (1982) underlines the importance of the Delphi Method as a "monovariable exploration technique for technology forecasting."

The Delphi Method is undertaken through the following steps:

1. Selection of a panel to participate in the exercise. Customarily, the panelists are experts in the area to be investigated.

2. Development of the first round Delphi statements.

3. Testing the statements for proper wording (e.g., ambiguities, vagueness).

4. Transmission of the first statements to the panelists.

5. Analysis of the first round responses.

6. Preparation of the second round statements (and possible testing).

7. Transmission of the second round statements to the panelists 
8. Analysis of the second round responses (Steps 6 to 8 are reiterated as long as desired or necessary to achieve stability in the results.).

9. Preparation of the consensus and conclusions (IIT, 2005).

The Delphi Method offers distinct advantages over the conventional face-to-face conference as a communication tool. Typical problems of group dynamics are bypassed. The interaction among the panel members is controlled by a panel director which prevents certain social interactive behavior. Furthermore, the anonymity of the panelists allows for unbiased responses void of groupthink and personal opinion influence (Martino, 1978).

\section{The Process}

Step One - Selection of the Panel Members. The selection of qualified panel members is crucial to the validity of the research. Panel members have been randomly selected from a list of pre-qualified candidates who were chosen based on their level of expertise in their given field as it may relate to architecture and the construction process. To be considered as a panel member, each candidate must have a high level of experience and history in the industry, be well respected in what they do, carry a proven record of success, and still continue to work today. A broad perspective from all facets of the construction and architecture industry was desired. Thus, panel members have been selected from the following disciplines:

- Architect (two panel members selected for affinities to the research)

- General Contractor (two selected for affinities to the research)

- Engineer (two selected for affinities to the research) 
- Construction Manager (two selected for affinities to the research)

- Specialty Contractor

- Attorney

- Owner - private sector

- Owner - public sector

- Banker

- Developer

The research primarily addresses the role of the architect and how it relates to the people with whom he works directly. The general contractors selected for this research represent the largest construction companies in the intermountain region who have a high level of experience in design-build and construction manager delivery systems. Therefore, the panel members have been weighted more heavily in certain disciplines as noted above. See appendix A for a list of the selected panel members.

Step Two - Development of the First Round Delphi Statements. The first round of statements has been developed to gain an understanding of the positions of the panel members. Thirty statements/questions have been formulated with multiple choice responses. The statements have been designed to extract knowledge and data based on the objectives of the research. In an attempt to avoid limiting the panel members in the information that they provide, and thus avoiding inaccurate conclusions, each multiple choice question has an option to write in their own information. See appendix B for a list of the statements. 
Step Three - Testing the Statements. The statements have been validated to ensure that they will provide accurate data. Each statement has been through numerous revisions to ensure that they will provide the data which is desired. Once the revisions were complete, the statements were reviewed by a group at Brigham Young University who tested the statements and validated them as being accurate and unbiased.

Step Four - Administration of the First Statements. It was then time to distribute the first round to the panel members. To accomplish this, a website was created in a multiple choice format. The link to the website was sent to each panel member via email. To avoid a lag in the time the data was collected, each panel member was asked to fill out the questionnaires, via the website, within two days.

Step Five - Analysis of the first round. Once the panel members were able to choose the response they felt was most correct, the data was collected, organized, and analyzed. The data for each statement was first collected and organized in a manner that the mean, median, and mode could easily be calculated.

Step Six - Preparation of the Second Round Statements. The second round statements are generated according to the responses received from the first round. The statements that received an $80 \%$ rate of agreement have been removed. These statements have been considered conclusive. All other statements have been considered nonconclusive and have been resubmitted in the second round. The statements were identical in the second round. Along with the statements, however, the percentage of each response 
chosen was included. The panel member, in light of the percentages and thoughts of the panel collectively, then had an opportunity to reconsider his response. In addition, a few new statements were added to gather additional knowledge based on the conclusive statements of the first round. See Appendix C.

Step Seven - Administration of the Second Statements. Second round statements were transmitted in the same manner as the first round.

Step Eight - Third Round Statements. A third round of statements was prepared, administered, and analyzed in the same manner as rounds one and two. See appendix D for the third round statements. 


\section{CHAPTER 4}

\section{FINDINGS}

The following is a compilation of the results of the Delphi rounds conducted with 13 panel members (see appendix A for a list of the members). The response rate, for the 13 panel members, was $100 \%$ for all three rounds of questions. Multiple choice responses were requested on 28 questions, and one question was a fill-in-the-blank. By the end of the third round, the panel members came to a consensus on 22 of the 28 questions (see appendix B for a list of the questions). Of those 22 , two received a $100 \%$ consensus. One received $92 \%$. Six received $85 \%$. Four received $77 \%$. Two received $69 \%$. Three received $62 \%$. Four received $54 \%$. The reader may assume that the responses fell along the lines of the professionals. It has been observed, however, that the responses were mixed, unbiased, and did not necessarily correlate to the chosen profession of each individual.

The data compilation is divided into five categories. The categories are: 1) historical background; 2) the current definition of the architect; 3 ) the current role of the architect; 4) factors impacting the architect; and 5) indications regarding the future role of the architect.

\section{Historical Background}

The role/responsibility of the architect has changed many times throughout history-both in the world and in the U.S.. Panel members were asked to identify the 
period of American history that has seen the most dramatic change in the role/responsibility of the architect (question one). The response was unanimous. The panel members completely agreed that the $20^{\text {th }}$ Century has seen the most change. The $20^{\text {th }}$ Century was a century of growth and business: Architectural firms began to survive the passing of their founders and operate as businesses, and technology and industrialization exploded in growth. In addition, new laws began regulating the construction industry. For example, laws were passed to allow design-build projects in the public sector, to consider the $\mathrm{CM}$ at Risk method, to recognize construction managers as professionals, and to select contractors based on qualifications.

Despite the unanimous consensus on the question about the $20^{\text {th }}$ Century seeing the most dramatic changes, the panel members have only been working in the industry for the past 20 to 30 years. Therefore, a more accurate predictor of the current trends and evolution, for this panel, would be to identify how much the role has changed throughout the past 20 years (question four). Nine (69\%) of the panel members stated that it is somewhat different than it was 20 years ago. Two (15\%) stated that it is very different and the remaining two (15\%) stated that there has been no change. See the chart below: 


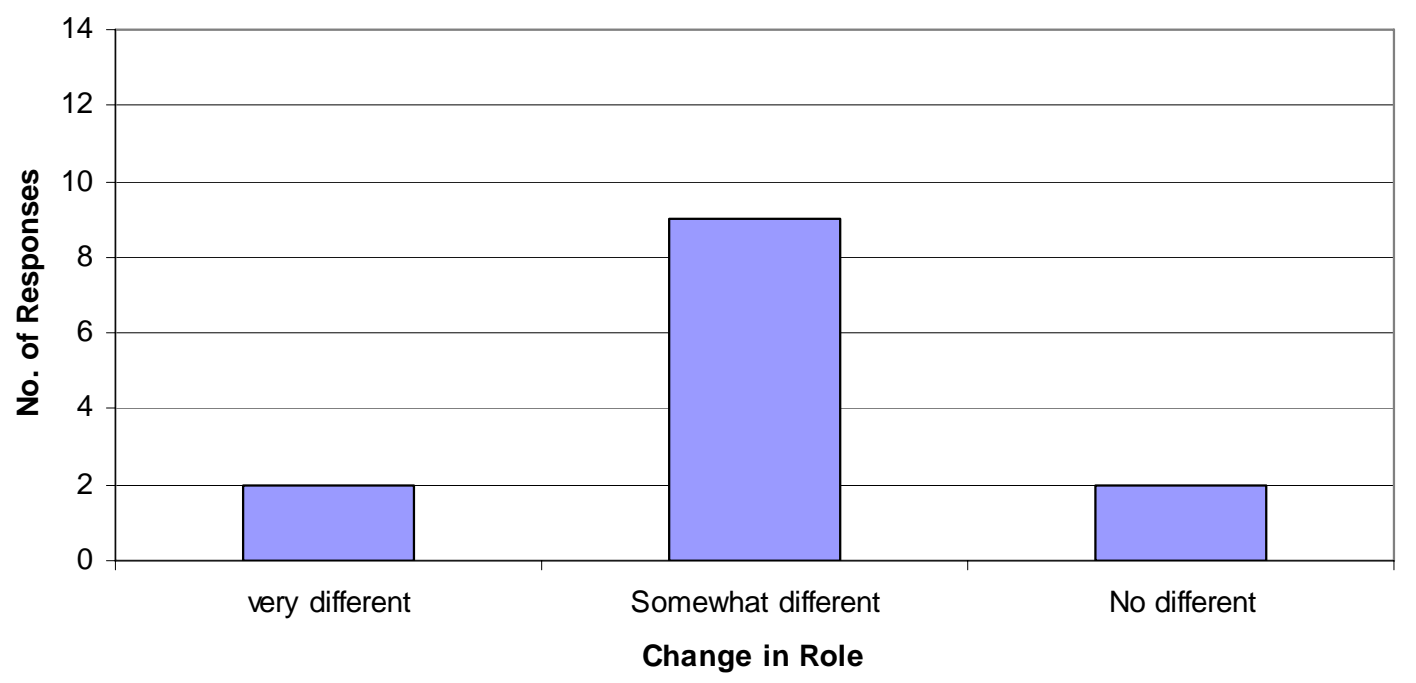

Figure 4.1: Difference in the Current Role of the Architect

\section{The Current Definition of the Architect}

According to the data gathered, the role and responsibilities of the architect have changed throughout time and have even seen changes just in the last 20 years. So where does that leave the current definition of the architect?

To determine the role of the architect and the direction in which it is heading, there must be an accurate definition from which to base any assumptions. MerriamWebster Dictionary (2006) defines the architect as "1) a person who designs buildings and advises in their construction; 2) a person who designs and guides a plan or undertaking." In question two, only two (15\%) of the panel members thought of the definition as being very accurate. The majority, eleven (85\%), thought the definition was somewhat accurate.

The exact role of the architect has become very hard to define. According to one of the panel members, "the field of architecture is very broad and complex...the questions, in some cases, try to simplify [the role of the architect] too much." With that in 
mind, an attempt to determine a more accurate definition was still pursued. Question 24 asked the panel members to select a more suitable definition of the architect today. The majority of the panel (11 respondents or $85 \%$ ) would define the architect today as "one who functions as the creator of the building's design." Of the remaining two panel members, one ( $8 \%$ ) selected "one who functions as the organizer of the building' design," and one (8\%) selected "other" and wrote "coordinator + creator." See the chart below:

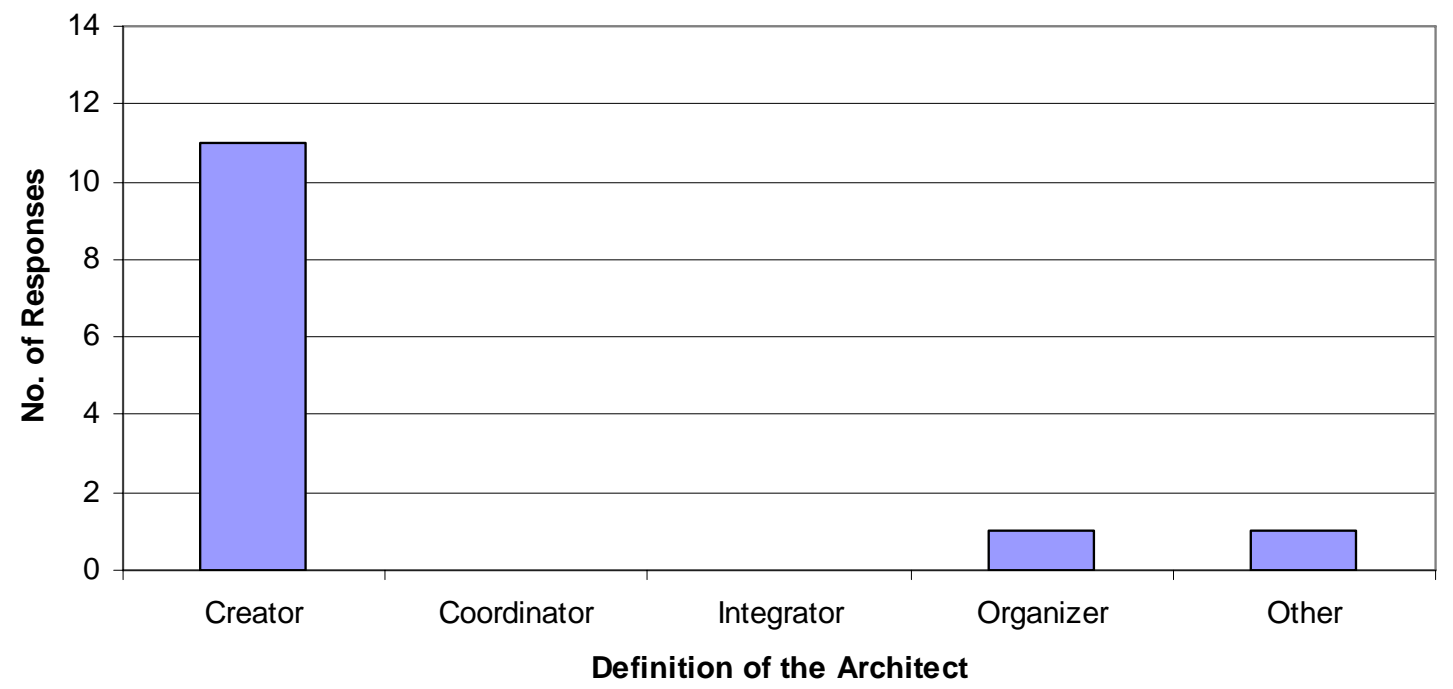

Figure 4.2: More Suitable Definition of the Architect Today

The Current Role of the Architect

Historically, the architect has managed a construction project from inception to completion and acted as a representative of the owner. The panel members were asked if the architect of today, with the complexity of projects and the current role, has become too specialized to oversee the project from inception to completion (question nine). Ten (77\%) of the panel members felt that the architect has not become too specialized and is 
still capable of managing the project from inception to completion. Two (15\%) panel members felt that it depends on the architect and stated that "different architects have varying levels of ability." And one (8\%) panel member felt that the architect is no longer qualified to perform this task.

As stated above, $77 \%$ of the panel believes in the architects capabilities to oversee a project from inception to completion. However, the panel was also asked which professional is better equipped with tools such as education, training and experience to properly oversee a project from beginning to end (question eight). In the response to this question, only two (15\%) selected the architect. Furthermore, the panel failed to come to a consensus on this question. In addition to the two that selected the architect, four (31\%) selected the construction manager, four (31\%) said that it "depends on each individual's talents, skills, education, and experience," and the remaining three (23\%) said that it needs to be a team approach. In selecting the team approach, one panel member elaborated by saying, "it takes an architect and a CM (construction manager) or GC (general contractor) working together for a successful project." See the chart below: 


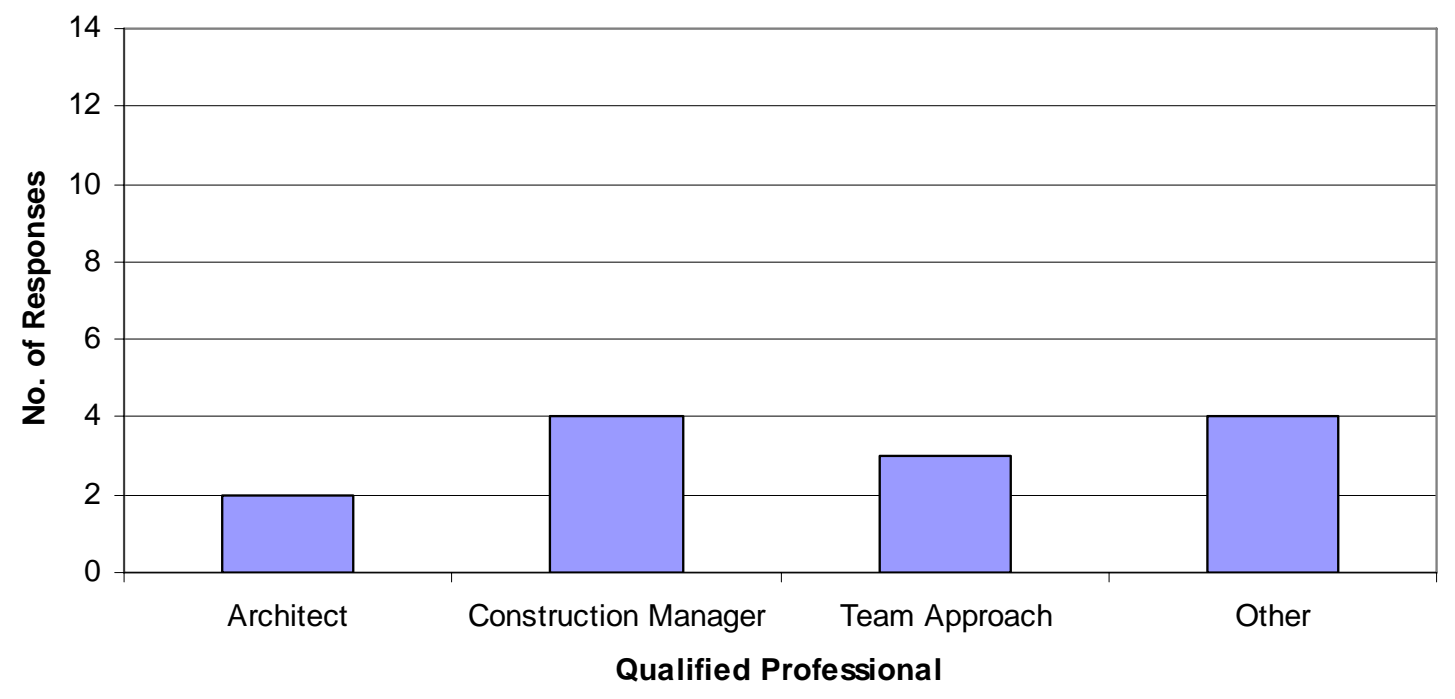

Figure 4.3: Qualified Professional for Construction Administration

The Architect and the Design Phase. The primary role of the architect, historically, has been someone who designs a building and then creates the drawings and details necessary to convey the design to the builder for construction. Projects today, however, have grown in complexity, scope and scale. Technology has added numerous components to a building that were non-existent just a couple centuries ago. The typical building project has also grown to be much larger than projects of the past. In light of these changes, is the architect of today still able to effectively detail the drawings to convey his design for proper construction (question three)? When asked this question, the panel was in complete unity in believing that today's architect is still capable of completing this task. However, six (46\%) of the panel members qualified their answer by stating that "the architect can lead/manage the detail effort, but must have significant outside consultant help." 
Roles During the Construction Phase. A successful construction project relies on the input of numerous professionals. Those that are involved during the construction phase include, but are not limited to; architects, general contractors, construction managers, engineers, consultants, sub-contractors, inspectors, developers, bankers, and building tenants. Each individual will donate crucial components to the final success of the project. Without the support of any one of these individuals at the proper time, the project will most likely fail. However, for the purposes of this research, it was still important to determine which professional; among the architect, general contractor, and construction manager, contributed the most to the overall success of the project during the construction phase. The panel members were asked to consider all types of delivery methods and to rate these three professionals as to their value and level of significance during the construction phase of the project (question six). Each professional was rated on a scale of one to five with one being the least significance to the success of the project and five being the highest. The results showed that the general contractor has the highest level of influence and contribution to the success. Twelve (92\%) of the panel members ranked the general contractor as a level five. The results for the architect and construction manager were more spread out without a consensus on any rating level. The most selected rating level for the architect, selected by six (46\%) panel members, was a significance level of four. The construction manager was pretty evenly spread between a rating of two and five with the most selected rating at level five (selected by five $-38 \%$ ). The table below illustrates the results: 


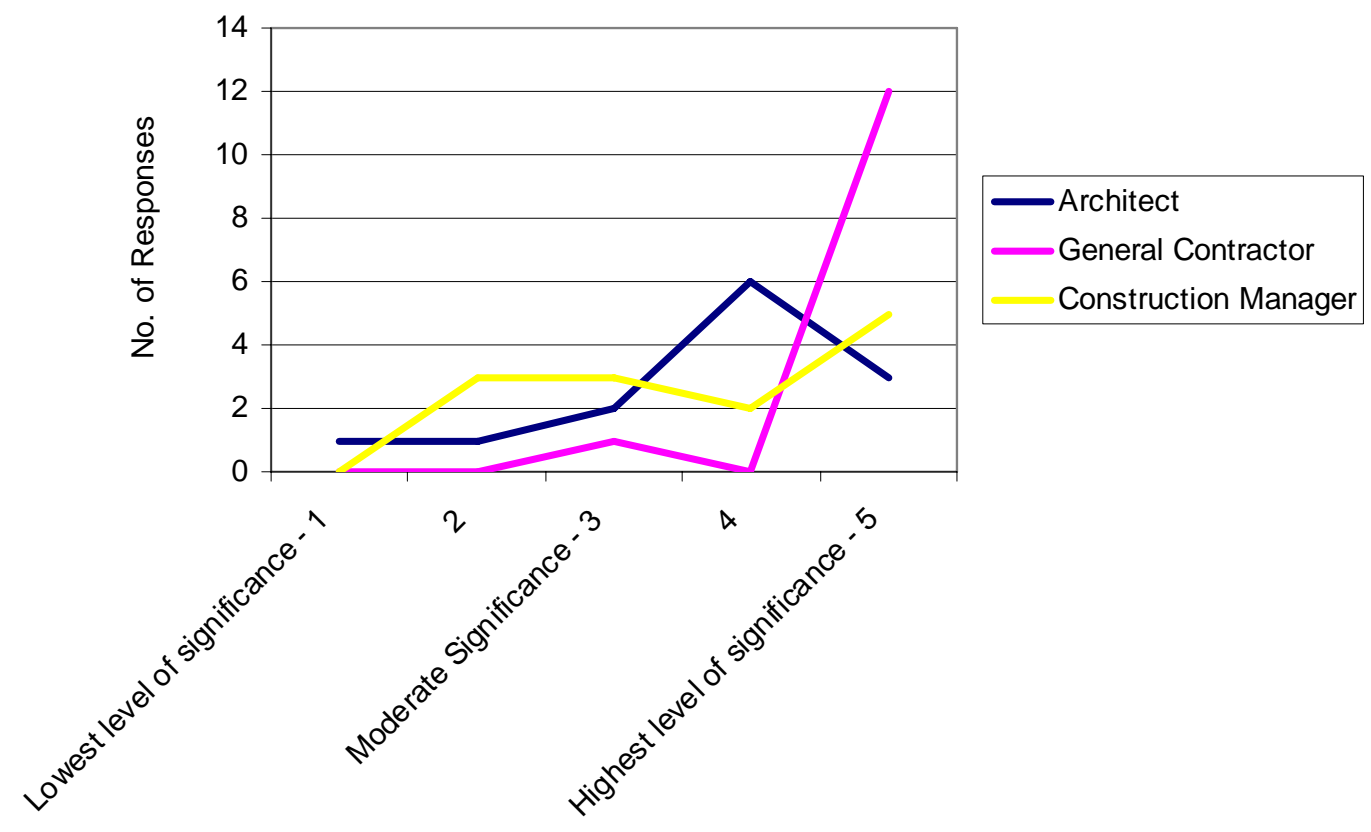

Figure 4.4: Professional Significance in the Construction Phase

Education of the Architect. Licensing for the architect of today, in most states, requires a graduate degree from a college that has been accredited by NCARB (National Council of Architectural Registration Boards). Upon graduation the licensing requirements are still not complete. In most states the graduate student must then complete both the Intern Development Program (IDP) and the Architectural Registration Exam (ARE). The IDP is a "systematic manner throughout the internship period that contributes to the development of competent architects." It is a program that consists of various training requirements that take a minimum of two years to complete. Its intent is to allow the intern architect to be mentored and learn the practice of architecture. The college curriculum, the IDP, and the ARE are all components of the licensing process that will lead to a registered architect. The licensing process is lengthy and, upon completion, designed to properly prepare the student to practice architecture. 
Concerns, however, have been raised regarding the curriculum and the proper education/preparation of the architect. Outlined by NCARB, the curriculum is weighed very heavily in design theory with the intent that the practical, hands-on knowledge will be learned during the IDP. To address this concern, the panel was asked whether or not they felt that the students who graduated from an NCARB accredited program are adequately educated for a career in architecture (question seven). Of all the panel members, three (23\%) said "yes" the architect is adequately prepared by the curriculum for a career in architecture. Four (31\%) said "no" the architect is not adequately educated. Another four (31\%) stated that schools provide the architect with proper design skills, but the student must then learn the technical and production skills through on-the-job training. The remaining two (15\%) panel members stated no opinion on this question. As a follow-up question, the panel was asked what additional education requirements would most benefit the architecture graduate student the most (question 26). Eleven $(85 \%)$ of the panel members felt strongly that there is a need for more courses addressing construction techniques. The remaining two (15\%) panel members selected other; one recommended construction management courses while the other said "all of the above with an emphasis on business management and construction techniques." The chart below displays the panel's recommendations: 


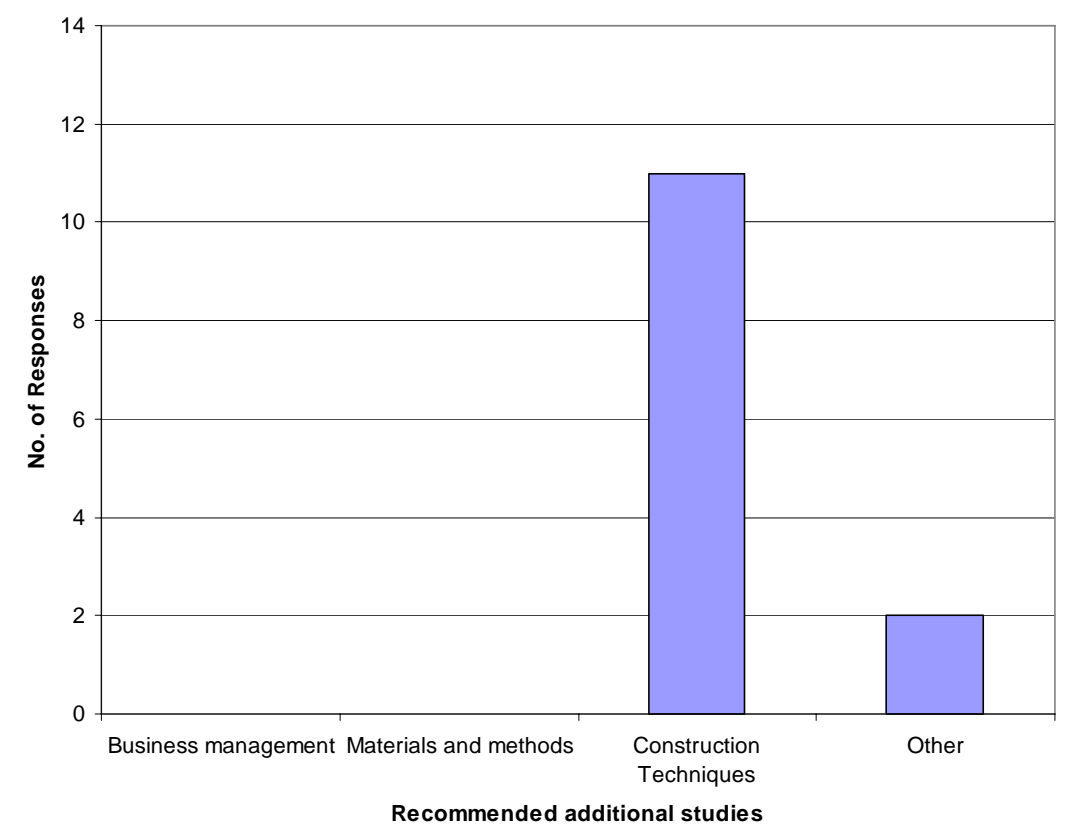

Figure 4.5: Recommendations for Additional Education

Factors Impacting the Architect

Some of the many factors that impact the architect can include legalities, collaboration and communication, conflicts, and new professionals becoming involved in the process. The panel members were presented with questions to clarify a few of these areas that impact the architect.

Legal Concerns. Lawsuits can devastate the schedule and budget of a project and become very costly to all parties involved. If an architect is not properly insured and protected, one single lawsuit could bring an end to his practice. All parties involved on a construction process should work with the highest level of integrity and strive to avoid any situation that could bring about a lawsuit. At times, unfortunately, situations arise where a lawsuit becomes necessary. With so many individuals involved on a construction 
project, it is not always clear who may be the responsible party. Because of this, construction lawsuits tend to attack every individual involved and then slowly eliminate each professional until the responsible party is uncovered. This is a costly process for everyone.

Lawsuits in the construction industry, and particularly those against the architect, appear to be on the rise. To validate this report, the panel was directly asked whether lawsuits against the architect are more or less frequent today than 30 years ago (question 14). Ten (77\%) of the panel members agreed that lawsuits occur more frequently today. Of those ten, seven (54\%) believe that the lawsuits are much more frequent and three (23\%) believe that the lawsuits are somewhat more frequent. Two (15\%) of the panel members, however, believe that lawsuits are much less frequent today and one (8\%) selected "other" and failed to respond to the question. See the chart below:

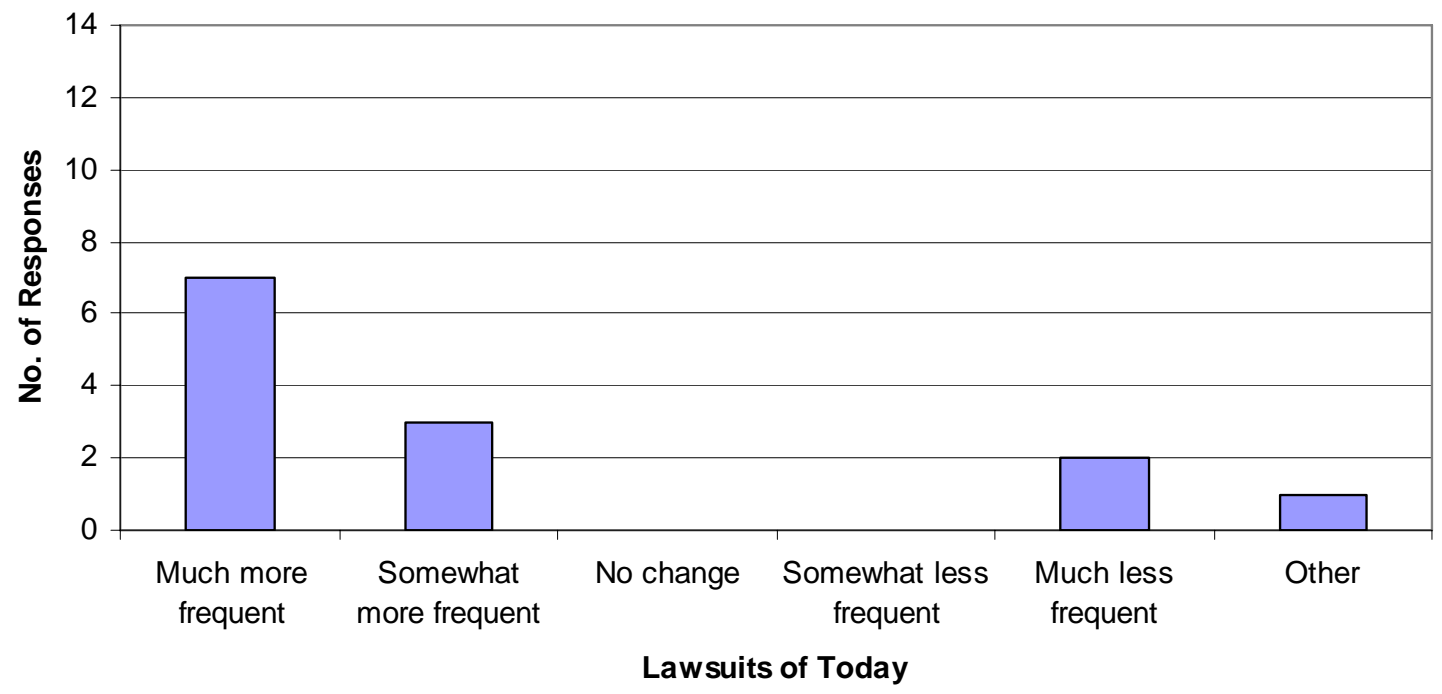

Figure 4.6: Lawsuits of Today vs. 30 Years Ago 
Errors and Omissions. Errors and omissions of the construction documents have long been a source of contention in the construction process. Prior to the establishment of the architect as a professional, the client had a legal right to expect a defect-free building. In the $20^{\text {th }}$ century, however, the professionals and the clients accepted the "standard-ofcare principle." This principle states that the architect is released of liability if he can prove that he acted with an overall professional standard of skill, knowledge, and judgment. What this means is that the owner no longer has the right to expect a defectfree building. If a defect in the construction is caused by an error in the plans, the owner cannot require the contractor to correct the issue without a change order. And if the architect followed the standard-of-care principle, there can be no recourse against the architect.

Regarding errors and omissions, the panel was asked three questions: 1) Are the laws fair and just; 2) what is the level of errors and omissions that are found in the construction documents, and 3) does the number decrease when a construction manager is involved.

The first question, posed to the panel, explains the standard-of-care principle and asks whether it is too lenient, fair and just, or too strict (question 15). Eleven (85\%) of the panel members feel that it is fair and just. Two (15\%) panel members felt that it is too strict and none of the panel members felt that it is too lenient. This information is also displayed in the chart below: 


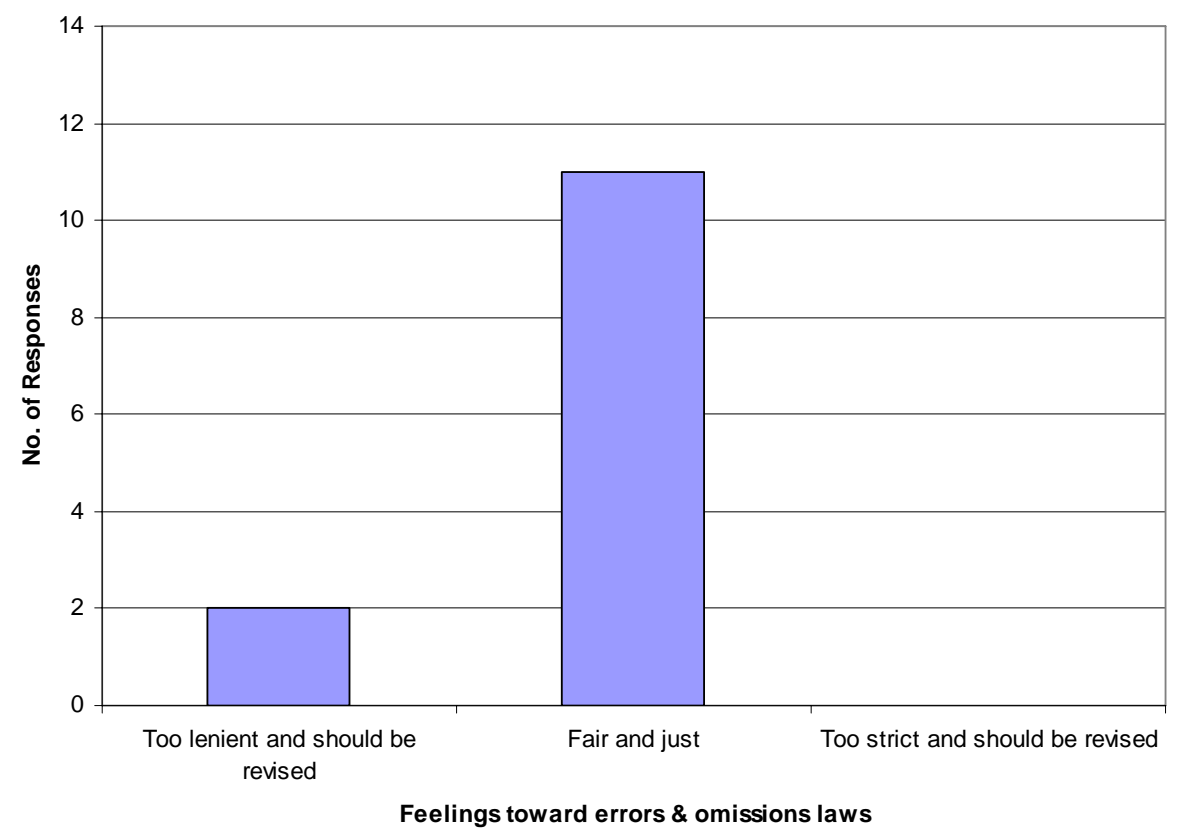

Figure 4.7: Errors \& Omissions and the Architect's Liability

It is not uncommon to walk onto a job site and hear a contractor complain that the drawings for the project are incomplete and full of holes, and that he would be on schedule and within budget if he just had a complete set of drawings. To validate this claim, the panel was asked about the number of the errors and omissions that can be found on a typical set of construction documents (question 16) and whether it is too high or too low. Seven $(54 \%)$ of the panel members felt that the number is higher than it should be with three $(23 \%)$ of the seven stating that it is "too high" and four $(31 \%)$ of the seven stating that it is "somewhat high." In contrast, four $(31 \%)$ of the panel members felt that it is "somewhat low" and one (8\%) felt that it is "very low." Another panel member $(8 \%)$ did not select one of the choices but wrote in that it "varies greatly between architects." The chart below represents these results: 


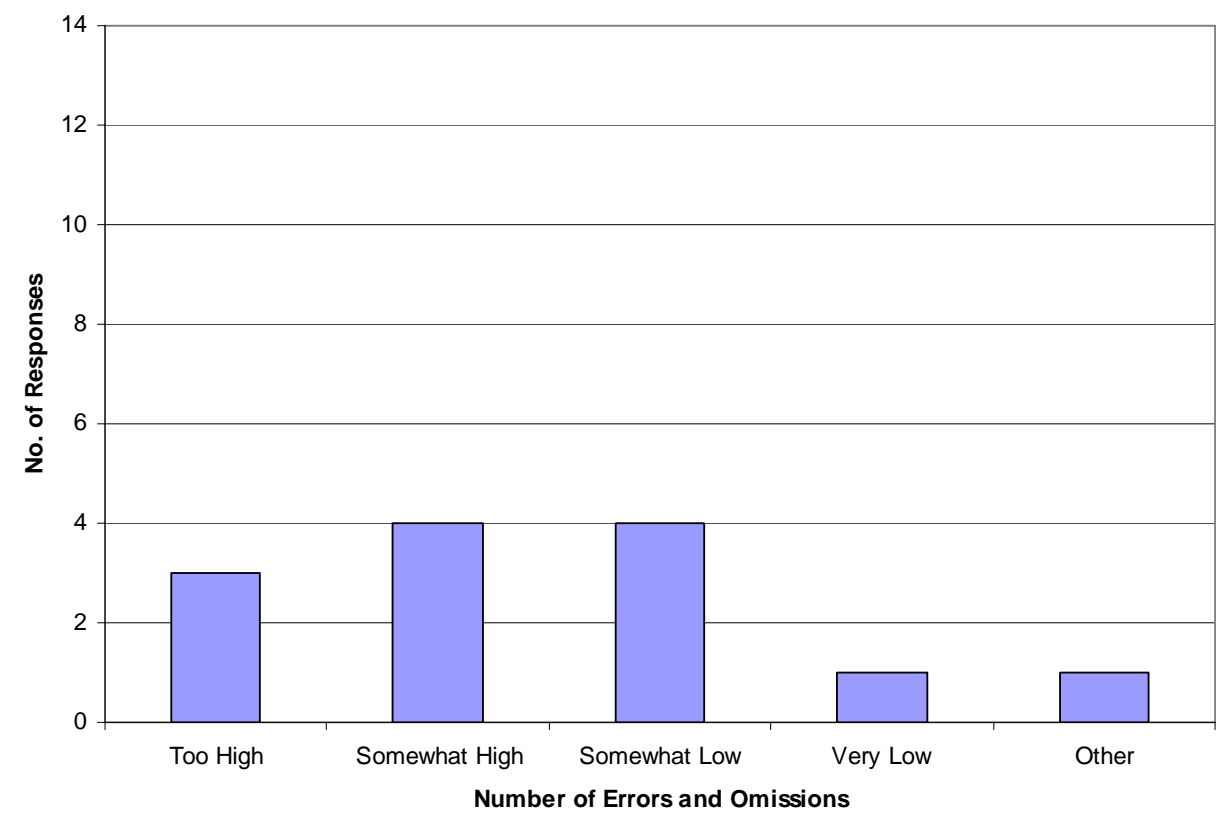

Figure 4.8: Level of Errors and Omissions in Construction Documents

One of the arguments in favor of the construction manager is that the he has the ability to provide construction technical expertise during the design phase. If this is true, one could assume that the level of errors and omissions would decrease with the involvement of a construction manager.

The panel was asked to compare the numbers of errors and omissions on a project in which a construction manager is involved to a project in which there is no construction manager (question 17). (This question only considers the benefits of a construction manager as it relates to errors and omissions and does not consider other potential benefits such as budget, scope definition, or schedule.) Eleven (85\%) of the panel members agreed that the number of errors and omissions decreases when a construction manager is involved. Of those eleven panel members, ten (77\%) felt that it is somewhat lower and one $(8 \%)$ felt that it is much lower. Two $(15 \%)$ of the panel members felt that 
that there is no change or benefit from a construction manager. See the chart below for the responses:

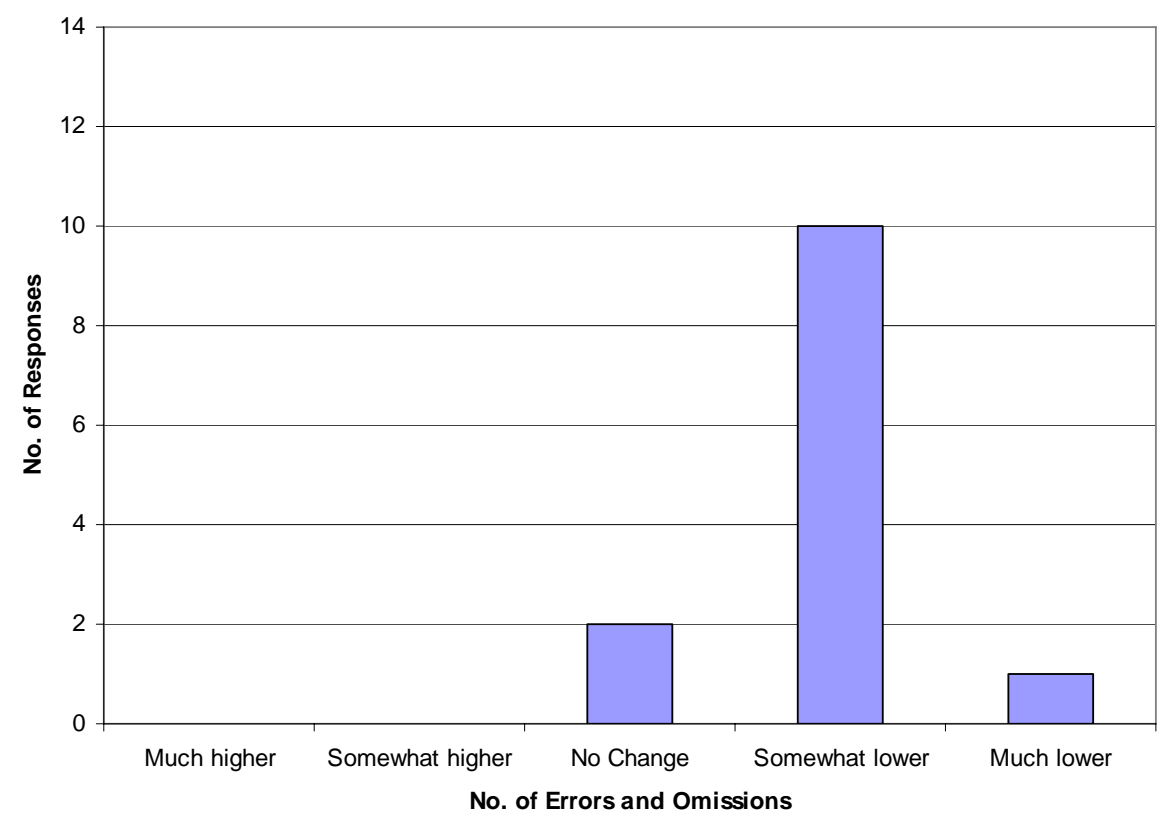

Figure 4.9: Level of Errors and Omissions with a Construction Manager

Conflicts and Communication. With the rising number of individuals that are involved on a construction project today, conflicts of role are becoming more prevalent. Professionals involved need to make sure there is always a high level of communication among all parties to ensure a quality project.

Considering all types of delivery methods and all phases of the process, the panel members were asked to identify the professional with whom the architect will most likely experience a conflict of role (question ten). Eleven (85\%) of the panel stated that the role 
conflict will occur with the general contractor. The remaining two (15\%) panel members believe that the conflict will occur with either the construction manager or the owner.

The main catalyst for contention between the architect and the general contractor, (question 13), according to the panel is poor communication (selected by $54 \%$ of the panel members). Other points of contention, as determined by the panel members and the percentage of the number of panel members who selected each point, are as follows:

- Poor communication - $54 \%$

- Different backgrounds and cultures $-14 \%$

- Project budget $-8 \%$

- Poor quality of performance from either party $-8 \%$

- Different goals and a misunderstanding of the concept of collaboration $-8 \%$

- Deficiencies and incompleteness of the plans $-8 \%$

To further try and identify the source of the role conflicts between the architect and general contractor, an additional question regarding collaboration was presented to the panel. The panel was asked to identify the level of collaboration that should take place between the architect and the general contractor on a typical construction project (question 12). Eleven (85\%) of the panel members believe that there should be more collaboration than presently found on a typical construction project. Of those eleven panel members, eight (62\%) believe that it should be much higher and three $(23 \%)$ believe that it should be somewhat higher. See the chart below for these results: 


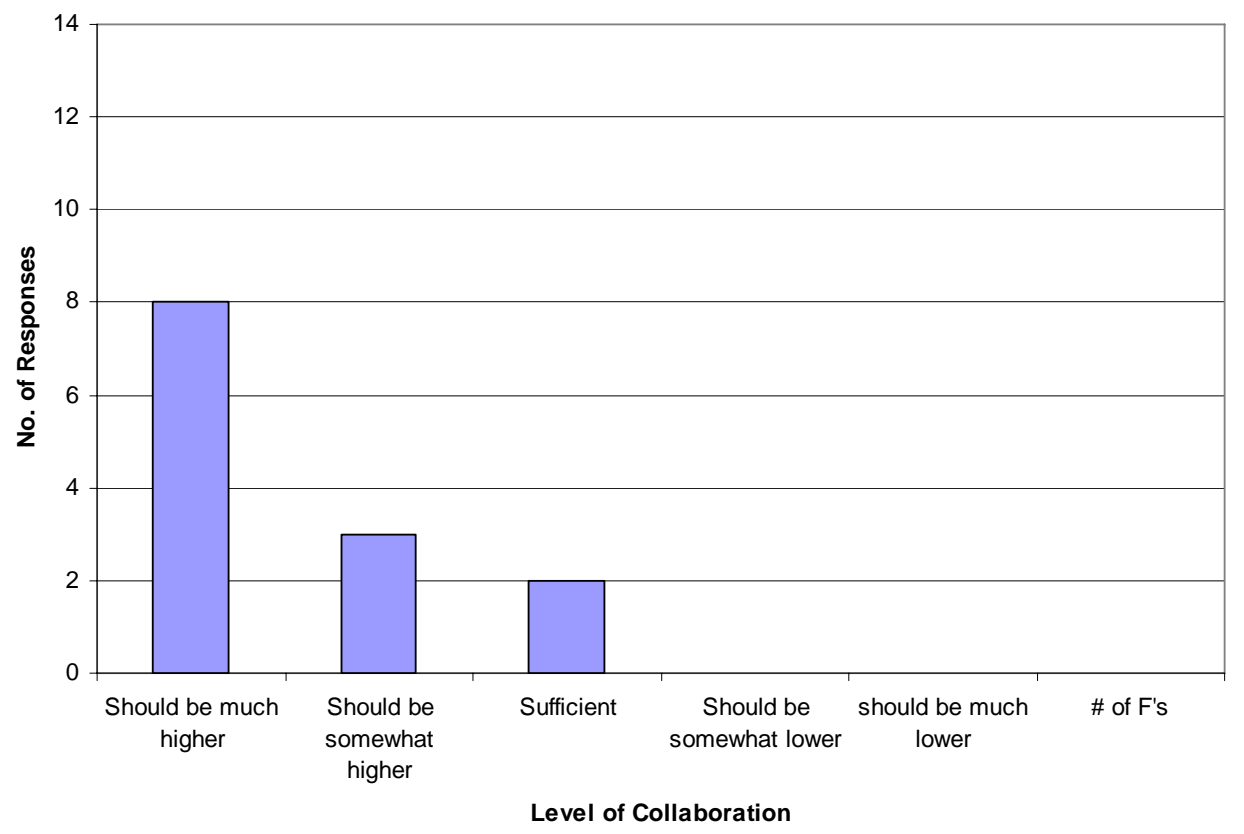

Figure 4.10: Collaboration of the General Contractor and the Architect

New Professionals. The most prominent new professional, that is impacting the role of the architect, is the construction manager. Considering the construction manager, the panel was asked three questions: 1) What is the level of impact that the construction manager has had on the architect; 2) has the impact been positive or negative; and 3) to what level should the construction manager be involved during the design phase.

The construction manager is a very young profession. The first claim to employ the services of a construction manager was in 1963 (Berman, 2002). The panel, in question 11, was unanimous in agreeing that the introduction of the construction manager has impacted the architect. The question continues to determine the extent of the impact. Considering all types of delivery methods, the majority of the panel (nine $-69 \%$ ), stated that the level of impact has been moderate. Of the remaining panel members, three $(23 \%)$ 
felt that it has been large and one (8\%) felt that it has been minimal. According to one of the panel members:

Construction management firms are getting more authority, responsibility, and are becoming more efficient in the scope of a full project. Architects are stepping back and allowing this to happen due to their concern about liability and their lack of performance, and that they are not keeping up with the modern trends of the construction industry"

The chart below represents the results:

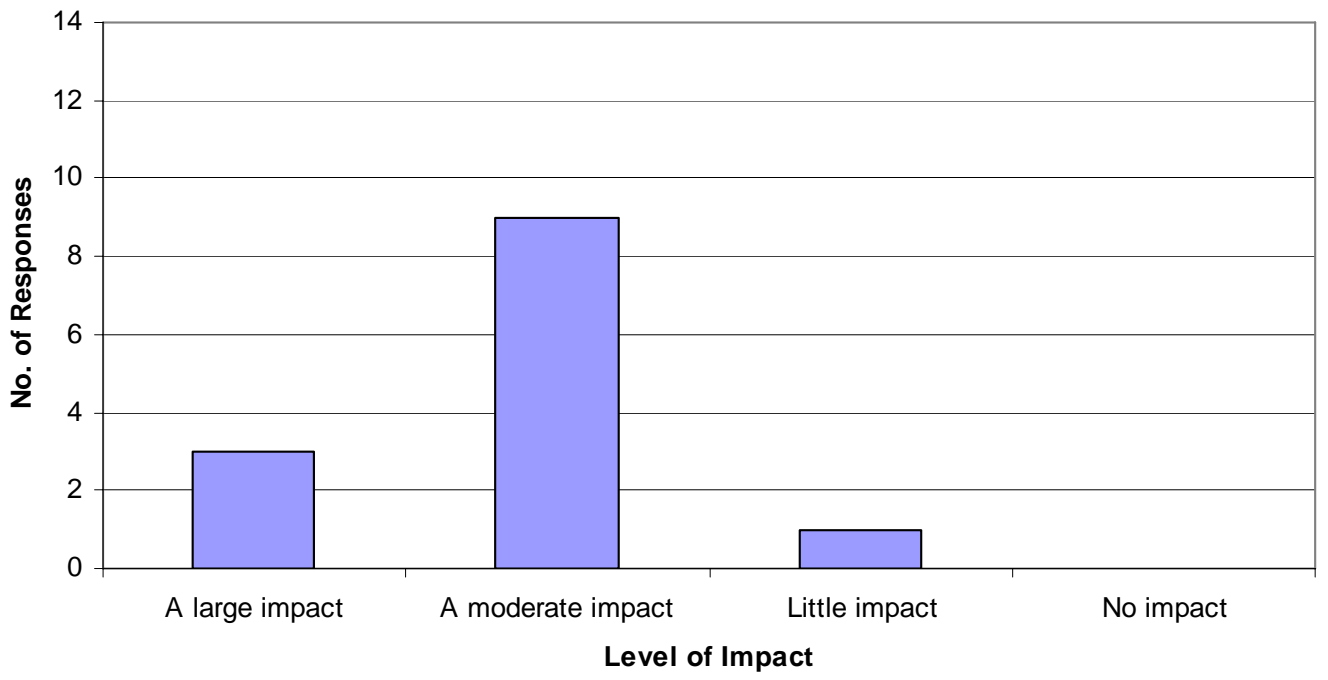

Figure 4.11: Construction Manager Impact on the Architect

Based upon the results above, that the construction manager has had a considerable impact on the role of the architect, an additional question was presented to the panel. The question was to determine if the impact has been positive or negative. The panel was asked to consider the impact from the perspective of both the architect 
(question 27a) and the owner (question 27b). Considering the design team, particularly the architect, twelve (92\%) of the panel members believe that it has been a positive impact. The remaining panel member did not select positive or negative. Instead, the following response/explanation was given:

It has narrowed the responsibility and, therefore, the broad base of knowledge that architects traditionally held. Additionally, it has fragmented the design process (and responsibility) so that many specialists contribute to the overall design. I don't think this is positive or negative from an architect's view, except that it has shifted responsibility and, therefore, liability to specialists who are better able to provide a higher quality of service. This may result in less compensation to the architect but also results in less liability to the architect. For most architects that are practicing architecture to make money, it may be [negative]. For architects that are practicing for the joy of the learned profession, it may be [positive].

Considering the view point of the owner, twelve (92\%) of the panel members also felt that the impact of the construction manager on the role of the architect has been positive. One (8\%) panel member continued to believe that the impact has been negative, from the perspective of the owner.

The final question, regarding the construction manager and its impact on the role of the architect, considers the level of influence/involvement that should take place during the design phase (question five). The panel completely agreed that there should be some level of involvement. The level of that involvement, according to the majority of the panel (eight $-62 \%$ ) believes that it should be high. Of the remaining panel members, four $(31 \%)$ believe that it should be moderate and one (8\%) felt that it should be minimal. The chart below displays these results: 


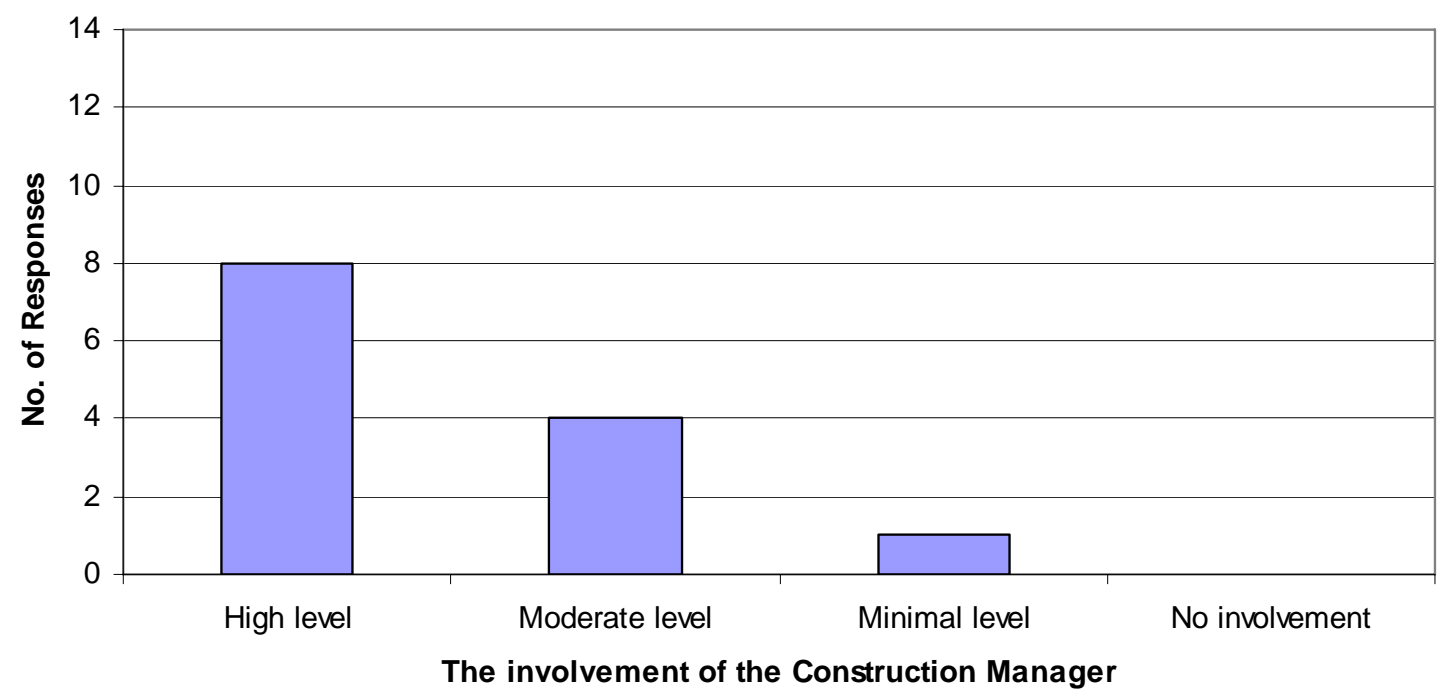

Figure 4.12: Involvement of the Construction Manager in the Design Phase

Additional Impacts. The field of architecture can be "very broad and complex." Within the limits of this research, it is not possible to determine all the factors that are impacting the role of the architect. However, the panel was asked to select the primary factor that has caused the role of the architect to change in the past 20 years (question 25). The responses varied and did not come to a consensus. The factors, along with the percentage of members who selected each factor, are as follows:

- A rise in liability and lawsuits $-38 \%$

- Lack of hands-on construction experience $-15 \%$

- The design-build delivery system - $15 \%$

- Involvement of a construction manager $-8 \%$

- New technology $-8 \%$

- System complexities $-8 \%$

- Cost control - 8\% 


\section{Indications into the Future of the Role of the Architect}

Given that the fact that the role of the architect has changed throughout history and particularly the past 20 years, it is quite possible that more changes will be seen within the next 30 years. The last set of questions that were been presented to the panel attempt to forecast the direction that the role of the architect will take within the next 30 years.

Change can either be a positive or negative evolution. The evolution of the role of the architect is on a track that is being laid by the influence of both history and current factors. Whether the direction of the architect's track is clear and positive is uncertain. To gain a better understanding of the direction, the panel was asked directly whether or not the role of the architect is clear and heading in a positive direction (question 21). Eleven $(85 \%)$ of the panel members believe that the role of the architect is not clear and is not heading in a positive direction. Only two (15\%) believe that it is heading in a clear and positive direction.

Building Owner. For the majority of projects, other than design-build projects, the architect is going to be working directly for the building owner. Therefore, a determination of the direction of the building owner can provide valuable indicators as to what is soon to come for the architect.

Building owners who build multiple buildings are going to be very interested in looking at ways to save time and money in their construction projects. In question 19 , the panel was asked about the most effective ways for the owner to save time and money (question 19). According to the majority of the panel (eight, or 62\%), the best way is to 
create standards or guidelines for all of their buildings. Five (38\%) of the panel members felt that the owner would benefit most from using the same design and construction team across each project. One of these five, however, qualified their response by saying that, "if saving time and money is the objective, it would be using the same design and construction team. For quality it would be creating standards or guidelines or hiring a program manager to oversee all of the projects."

Design-Build. Design-build is a delivery method that has been gaining popularity as it is developed and refined. In this delivery method, the building owner will execute one contract for both the design and the construction of a project. The architect clearly has a higher level of knowledge in the design phase and is better suited for that role. Conversely, the contractor clearly has a higher level of knowledge in the construction phase. The question that was presented to the panel was to determine which professional is more qualified to be the prime contract holder and lead a design-build project (question 18). The panel did not completely agree as to which professional is more qualified. Six (46\%) of the panel members would choose a general contractor to be the lead. Three (23\%) would choose an architect, two (15\%) would choose a construction manager, and two (15\%) said that they would "select the most qualified individual." The chart below displays the results: 


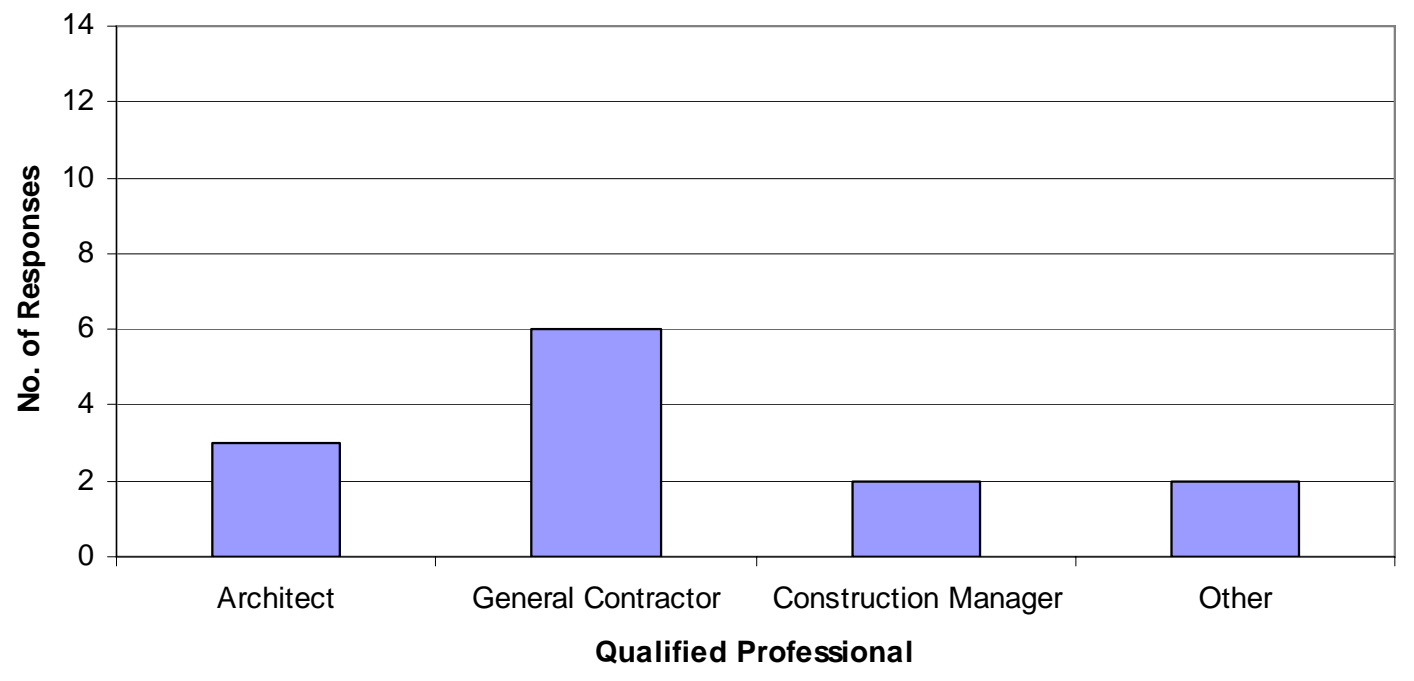

Figure 4.13: Design-Build and the Lead Professional

Fragmentation and Specialization. Anytime a process becomes broader in scope and more complex, it requires specialists for certain aspects. When specialists are appointed to oversee a certain aspect of a professional's role, it leads to fragmentation of that role. This has occurred in the construction process with the general contractor and sub contractors. It is also evident in the design phase with the growing number of consultants involved on a typical project.

Fragmentation and specialization are unavoidable factors that will impact the role of any professional that is involved. The question, however, is whether or not this fragmentation and specialization will harm the art of architecture and eventually lead to its demise (question 20). The panel could not come to a consensus and was actually split right down the middle. Seven of the panel members said "yes" it is leading to the demise of the art of architecture while six said "no." To determine why the panel could not agree 
on this item, further clarification was requested to reinforce the responses. The explanations from those who said "yes" are:

- The architect at one time led the design-build process. Over the years, architects and other professions have either given up or lost aspects of the design process, the estimating, the engineering, and so on. Today with specialization, some organizations only produce documents and no design; others design and do not do produce the documents. Systems are more complex and the architect delegates the design and implementation to others. An architect must understand the whole to design the parts; the art is the dealing with the whole concept, not just the parts.

- The need for higher quality details and specs has led to architects that specialize in these areas while other architects are more "design" oriented.

- The need for an architect to specialize and concentrate in one area takes him away from his role as the "Master Builder" that knows all aspects of the project from beginning to end.

The explanation for those panel members that selected "no" are as follows:

- Not much fragmentation or specialization is seen, at least not anything that detracts from the Art of Architecture. I think the Art of Architecture is mostly affected by cost more than anything. How much money an owner is willing to put into a project or is able to put into a project determines how much architecture goes into a building.

- There are other matters that are more significant in the change than fragmentation and specialization. Of greater importance might be lack of willingness to lead out due to liability fears. Another is that creative 
training may be lacking; perhaps due to computer training and new methods of production. Outsourcing of drafting is also a factor.

Design vs. Production Architect. On large-scale projects, it is common to have a design architect who works out the schematic design and a separate production architect who creates the actual construction documents. In this manner, the two architects are able to focus more on their specialization. The panel members were asked if they feel that this is a growing trend that will gain popularity and be seen more often in the future (question 22). Ten (77\%) of the panel members said "yes" and two (15\%) said "no." One (8\%) of the panel members choose neither yes nor no and said, "I would hope that the same architect works on the project from design through construction."

Additional Comments. The final question, for each of the panel members, was an open ended question that allowed the panel to elaborate on their responses. The question was; in what direction do you see the role/responsibility of the architect going within the next 30 years (question 23). The responses are as follows:

- The architect needs to take back his/her role as the architect, the vision maker, the conductor. The architect also needs to be more proactive with the general contractor and include his skills during the design process. The architect needs to be compensated to do all that he/she is expected to do.

- I believe that the role of the architect will lead to collaboration and to bring all participants together to address complexity. The architect will still design and 
document, but will have less to do with estimating and just work with the build team to see it through.

- It is becoming a clip art profession with the real effort being left to the construction industry to make it work. This will continue.

- First, architects will be working more and more in design/build and construction management project delivery systems and taking more direction from construction managers and general contractors while still providing creativity and technical information. Second, some contractors who claim to be Design/Builders do not really understand the whole concept of $\mathrm{D} / \mathrm{B}$ and the role of a true $\mathrm{D} / \mathrm{B}$ contractor. Therefore, they fail to provide the benefits to the owner that they deserve. This will cause some owners and architects to revert back to "Old School" Design/bid/build.

- The number of [the architects] responsibilities are growing.

- The architects will have to have a broader knowledge of all aspects of a project.

- I think the architect will have to become a much better manager of time, people and consultants as everything becomes more and more complex and specialized. The requirement to farm out most of the parts and pieces of the design, due to complexity/specialization, might require architecture firms to become more of an architecture manager rather than an architect.

- I believe that collaboration of owners, architect, engineers, contractors, and subs is crucial to a successful project. I think that the architect will become more of a team player in the future. 
- More specialization and less responsibility for the design work of other consultants.

- Construction management firms are getting more authority, responsibility, and are becoming more efficient in the scope of a full project. Architects are stepping back and allowing this to happen due to their concern about liability, their lack of performance, and that they are not keeping up with the modern trends of the construction industry.

- The architect must be more diversified and be willing to work with construction managers, general contractors and others while maintaining the leadership role on the design portion of the project. The architect will work with the contractors to assure the intent of the design is obtained; the owner's representative.

- Architects are their own worst enemies. They often don't understand business or costs and are so risk adverse that they seldom take the lead role that they should. Successful firms in the future will be those that breakout of the mold of being "designers" only. 


\section{CHAPTER 5}

\section{CONCLUSIONS AND RECOMMENDATIONS}

\section{The Architect of Today}

The New Architect. The definition of the architect today has evolved and is different than any other time in history. The architect's role and responsibility have changed even in the last 20 years. His primary function, however, has remained constant throughout history and still holds true today.

Architecture has always been defined as "the art and science of designing and erecting buildings." The results from the research show that the primary function of the architect of today is still considered to be the "creator of a building's design." So while the changes in recent history have not been paradoxical to the profession, they have been significant enough to create confusion as to the exact responsibilities and the expectations placed on the architect. According to the panel, "the field of architecture has become very broad and complex" and has become unclear as to its direction. An unclear definition of the architect presents false expectations of the architect's performance which leads to role conflicts, poor results, and dissatisfied customers.

Factors Impacting the New Architect. In the past 20 years, there have been numerous factors that have influenced the direction of the architect. Many of these factors will continue into the next era and affect the direction of the architect. 
When the panel was asked to name the primary factor that has influenced the architect's role and responsibility, a consensus could not be reached. The panel was asked to select one of three responses. However, the results returned seven different responses (question 25). The construction industry is constantly growing and is developing into a more professional, white collar industry. It is attracting more educated individuals, and it is growing in complexity. There are considerations today that did not exist 100 years ago. Factors such as new technology, a rise in lawsuits, the introduction of the construction manager, the level of compensation, and the design-build delivery system have all influenced the architect in recent history. And they will likely continue to affect the architect in the future.

This evolution of the construction industry is requiring a great determination for professionals to stay current and cope with new factors as they arise. One of the panel members, while discussing the impact of the construction manager, stated that "they (the architects) are not keeping up with the modern trends of the construction industry."

Education. Only three (23\%) of the panel members felt that the architectural education curriculum adequately prepares students for a career in architecture. The requirement of the IDP provides hands-on experience in a design office which helps to better prepare the student for a career. However, 11 (85\%) of the panel members still feel that the student would benefit from construction-technique courses tied into the curriculum or development program.

When the panel was asked to select the professional who is more qualified to properly oversee a project from inception to completion, only two $15 \%$ selected the 
architect. This is a surprisingly low number considering that this has traditionally been a key role of the architect. Another seven (54\%) of the responses were divided between the construction manager and a team approach. The remaining four (31\%) panel members said that it "depends on each individual's talents, skills, education, and experience." Perhaps a correlation can be made between the third of the panel that are unsure whether the construction manager or the architect is more qualified and the recommendation of the panel to provide more construction-technique experience to the architecture student. By providing the architecture student with construction-technique experience, either in the curriculum or the IDP, the graduate student would be better equipped to oversee the entire project and not be restricted to the design phase.

Collaboration and Communication. An interesting result of this study is the discrepancy between the actual and the perceived-and-desired level of collaboration and communication. On any given project, $11(85 \%)$ of the panel members said that there should be a higher level of collaboration. So if architects, general contractors, construction managers, engineers, and sub-consultants all agreed that there should be a higher level of collaboration, then why isn't there? Perhaps the reason is poor communication which, according to seven (54\%) of the panel, is the main catalyst for contention between the architect and general contractor. Once again, however, architects, general contractors, construction managers, engineers, and sub-contractors all agreed that poor communication is a point of contention. So if all parties know that it is a problem, why is it still occurring? 
The construction process, by nature, is contentious and has been so for many years. One of the roles that the architect plays, in the traditional delivery method, is the owner's representative during the construction phase. In this role, the architect holds the responsibility of inspecting the work of the builder down to the smallest details and ultimately being the one who accepts or rejects the work. This role creates an adversarial relationship between the architect and the contractor. Furthermore, in the traditional delivery method, the contractor bases the project estimate and budget on the construction documents provided by the architect. Any omissions or inaccurate details will take away from the accuracy of the budget, drive the project cost up with change orders, and delay the schedule while changes are made. All of which can chip away at the profit of the builder.

This research shows that the lack of collaboration and communication is a problem. According to one panel member, "the collaboration of owners, architect, engineers, contractors, and subs is crucial to a successful project." In support of this, the panel was asked which professional is better equipped to manage a project (question eight). A consensus could not be reached. Yet when the panel was asked how much involvement the construction manager should have during the design phase (question five), the entire panel agreed that there should be some level of involvement. This unanimous response, along with the inability to select any one professional, suggests that there needs to be a team approach to have a successful project.

The identification of the problem, however, is easier than the implementation of the solution. It is evident that there needs to be a team approach. "It takes an architect and a $\mathrm{CM}$ (construction manager) or GC (general contractor) working together for a 
successful project." Design build, at least for this particular problem, appears to be one solution that can create the desired team approach. Design build places the architect and the builder on the same team, eliminates the adversarial relationship, and elevates the level of communication and collaboration.

The construction manager may be another solution to the problem. According to James Adrian (2004), the most important potential benefit of the construction management process is to "reduce adversary \& head toward a team approach." Supported by the fact that the panel felt strongly about the construction manager being involved in the design phase and that errors and omissions are lower whenever a construction manager is involved, the solution may just be the development of a stronger construction management process.

Another obstacle in implementing a team approach, may be in overcoming established stereotypes. The traditional delivery method has been in use for quite some time. The adversarial relationships have been considered to be part of the job and have become well rooted. It will take a paradigm shift to enable the various professionals to realize that people no longer want the adversarial relationships and that, in fact, everyone wants the same thing - a team approach.

\section{The Architect of Tomorrow}

Only two (15\%) of the panel members said the role of the architect today is clear and heading in a positive direction. This statistic should draw immediate attention to the profession and urge architectural professionals to consider its direction and see what can be done to improve it. The last question presented to the panel was an open-ended 
question that allowed the panel members to freely express their perception and prediction of the architect's direction within the next 30 years. The responses were very insightful. Without any instruction or prompting, about half of the panel members said the architect's role will be drastically harmed if it continues on its current path. The other half provided suggestions and insight as to what the architect needs to do to improve upon its status and direction.

Indications of the Direction of the Architect. If the architecture profession continues on its current path, the panel collectively agrees that its role will become more specialized and carry less responsibility. Panel members agree that the architect will still be responsible for the design and production of the documents, but will have less to do with estimating and other construction related duties. The architect will "work more in design build and CM delivery systems and will take more direction from the $\mathrm{CM}$ and GC" while still providing "creativity and technical information." One panel member states, "It's becoming a clip-art profession with the real effort being left to the construction industry."

The reason for this direction, according to the panel, is the fact that architects are stepping back, whether it is intentional or not is unclear, and allowing CM firms to assume their role. “Architects are their own worst enemies. They often don't understand business or costs and are so risk adverse that they seldom take the lead role." The construction manager has been innovative and found ways to improve on efficiency throughout the project. The $\mathrm{CM}$ firms are gaining more authority and responsibility. Meanwhile, the architect has allowed this management shift because of "their concern 
about liability, their lack of performance, and ...not keeping up with modern trends of the construction industry."

Suggestions to Improve the Direction of the Architect. The panel agreed that the future of the architect is unclear and heading in a negative direction. However, many panel members believe that the architect can change this direction by taking back the role as the "vision maker" and the "conductor" of the project. Numerous things can be done, and will need to be done, by the architect to change its direction. First, the architect must be more diversified and acquire "a broader knowledge of all aspects of a project." Second, the architect will have to "be more proactive with the GC and include his skills during the design process. He will need to "be willing to work with the CM's and the GC's while maintaining the leadership role on the design portion of the project." Third, the architect will need to develop business skills. As projects become more complex and specialized, there needs to be someone who can manage all aspects of the design, including "time, people, and consultants."

Successful firms in the next 30 years will be those that "break out of the mold of being designers only" and look at ways to reclaim their lost responsibilities and also explore new alternative services. New alternative services could come from specialization from growth and complexity, or from the needs of building owners.

Specialization is continuing to fragment the industry. Architects should be aware of this and address it according to the needs of the project. According to $69 \%$ of the panel, the separation of the architect's role into a design architect and a production architect will continue to grow and will be seen more often in the future. 
Building owners, just as the construction process, are continuing to evolve and change. At times, new needs will arise from the owner and he will be looking for someone to fulfill that need. According to eight (62\%) of the panel members, building owners will be looking more for someone to create standards and guidelines for their buildings.

Corporations such as Target deliver more than 110 new stores and 80 remodels across the country every year. "To ensure consistent improvement they have developed evolving standards, prototype building designs and a well-populated cost history database for estimating new projects" (Thomsen, 2006). Facilities such as Rice University are able to create great buildings through world-renowned architects. However, the campus has recognized that strong design-oriented architects were focused only on design. For that reason, Rice University will hire another architecture firm that is "skilled at construction documents and project management as the executive architect." The design firm will then become a sub-contractor to the executive architect. The executive architect will create the standards and guidelines for the project and then continue to manage the design architect (Thomsen, 2006). The introduction of a program manager or executive architect fills a need of the building owner and provides new opportunities for the architect.

\section{Recommendations for the Industry}

Recommendations for the professionals who work in the construction industry and those who have a professional connection to the architect have been formulated based on the results of the research process. 
The position of the architect has become very broad and complex. As such, it is recommended that the role of the architect be clarified and re-defined on every single project. If a standard agreement form from AIA, AGC, or CMAA is used, a careful review should be conducted to ensure that no conflicts of role will occur.

It is recommended that the construction industry continuously work toward a higher level of collaboration and communication. Construction projects have grown in size and complexity and will continue to do so. The success of these projects will increasingly rely upon the level of collaboration among the team members. It is not uncommon for construction projects today to have contributions from $100+$ specialists and professionals. Many of the professionals involved have the power to make decisions that impact the entire project. Communication must be constant among the numerous decision-making professionals to ensure success. The research results demonstrated that the industry is lacking in communication and that a higher level of collaboration is desired by everyone. The construction industry needs to discard its feelings of adversarial relationships and continuously move toward a team approach.

It is recommended that the education and licensing process of the architect be examined and the effectiveness of the program analyzed. The architect of the past spent many years learning technical construction skills prior to becoming a master builder. The panel felt strongly that the architecture student could benefit from additional construction technique courses. Options of reformation or improvement to the architect's licensing and registration process could include:

- An undergraduate degree in construction management prior to pursuing a Master of Architecture. 
- Include requirements for hands-on experience in construction techniques, estimating, and scheduling in the IDP (Intern Development Program).

- The option of specialization of the architectural degree similar to MBA (Master of Business Administration) programs which offer specialization in finance, marketing, operations, international relations, accounting, information systems, human relations, etc.

\section{Recommendations for Additional Study}

The intent of this research was to determine the position of the architect in the construction process today and gain insight into its direction. The research attempted to provide a wide angle view of the role of the architect. Many of the factors impacting the architect, today and tomorrow, require a more intensive study to form additional conclusions. The following are suggestions for additional research topics.

Additional research is recommended to address the relationship between the architect and the contractor. The relationship was established centuries ago; right after the master builder fragmented into a designer and a builder and has been a source of many conflicts on construction projects. A study of this relationship could provide insight into the reasons why communication is so poor between the two professionals and continues to be poor when both parties agree that it should be better. It could also provide insight on how to improve the relationship.

Additional research of delivery methods and collaboration is recommended. Many of the panel members repeatedly stated that successful projects require a team approach. 
A productive study would be to examine possible delivery methods and the level of teamwork that is fostered by each delivery method.

Additional research of design-build is recommended. Design-build is a delivery system that appears to resolve many of the liability and teamwork concerns. However, since the introduction of design build, the predictions of its growth have fallen short of what was expected. According to one panel member, "some contractors who claim to be design-builders do not really understand the whole concept of design-build and the role of a true design-build contractor. Therefore, they fail to provide the benefits to the owner that they deserve. This will cause some owners and architects to revert back to "old school" design-bid-build." It would be a valuable study to confirm this statement and determine exactly why design-build has not been as great of a solution as it was thought to be. Furthermore, the panel could not come to a consensus as to who is more qualified to lead a design-build project. The trend tends to favor the general contractor. However, what benefits could an architect or construction manager provide as the lead that the general contractor could not?

Additional research of lawsuits and liability is recommended. The panel stated that one of the primary factors that have impacted the role of the architect in the last 30 years has been lawsuits and liability. However, eleven (85\%) of the panel members felt that laws regulating errors and omissions are fair and just. Additionally, only three (23\%) of the panel members felt that the level of errors and omissions, in a set of construction documents, is "too high." A valuable research topic would be to determine the types of lawsuits that are occurring, to what extent they are impacting the industry, and what trends or patterns can be found in the lawsuits against the architect. It would also be 
beneficial to determine if the number of lawsuits is actually rising, or if it is a perceived rise.

Additional research of new roles and trends of the architecture industry is recommended. Trends that are beginning to appear, such as the fragmentation of the architect into a design architect and a production architect, are new and have had very minimal research. Additional study is necessary to analyze its pros and cons.

Additional research that is restricted to the perceptions and feelings of the architect is recommended. This research study attempts to determine the role of the architect from the perspective of the collective construction industry. An interesting study would be to limit the research to the point of view of the architect. A concentrated study of the architect could provide insight into their feelings toward the direction of the architect, whether the shift has been voluntary or involuntary, and what the profession plans to do to address the shift.

\section{Implications}

The information obtained in this research has provided insight into the role of the architect, the factors impacting the architect, the direction of the architect as it relates to the construction process, and the construction industry's perception of the architect. After analyzing the data and the results of the study, a number of implications have been made.

There has been a shift in the role of the architect. Overtime it has evolved and been re-shaped and re-defined. The changes of the past may have been a positive influence on developing the architect as a profession. However, the path on which the role is heading today is not clear and is not in a positive direction. 
The role of the architect will continue to fragment to address the demands of the construction projects. Large projects require a certain level of specialization for success. The higher level of expertise and benefits of specialization are also being recognized and carried over to smaller projects. The industry is seeing an increasing level of separation of the design architect, the production architect, and the program manager who creates the standards and guidelines.

The expertise of the construction process is shifting from the architect to the construction manager and/or builder. With the traditional delivery method, building owners would first approach the architect and rely on him as the expert through the entire project. Today however, builders are being selected based on qualifications and construction managers are becoming involved in the early phases of the project. This is a result of the owner relying more on the builder or construction manager as the expert to guide the owner through the construction process. If the architect is to regain its status, it must improve upon its knowledge of construction techniques, develop its management skills, and approach its role as being innovative and dynamic. Otherwise, the role of the architect will continue moving toward a sub-contractor position to the builder and/or construction manager.

Construction projects now require a higher level of collaboration and communication - a team approach. There is both a desire and a need for a higher level of collaboration in the construction process today. The final success of the project will depend on the level of collaboration realized during the project. 


\section{BIBLIOGRAPHY}

Adrian, J. (2004). Construction Productivity: Measurement and Improvement. Champaign, IL: Stipes Publishing L.L.C.

AGC 510 (1997). Standard Form of Construction Management Agreement Between Owner and Construction Manager.

AIA Document A201-1997 (1997) General Conditions of the Contract for Construction.

Berman, G. (2002, October 13). The Morphing of the Architect's Role and how it is Impacting the CM. CM eJournal, 1-35.

Berman, G. (2003). Are Foxes Watching the Owner's Hen House? An Examination of the Architect's and Construction Manager's Roles in Managing \& Administering the Design \& Construction Process. CM eJournal, 1-27.

Bridging (2003). 3D/International. 3D/University Essays.

Briggs, M. S. (1974). The Architect in History. New York: Da Capo Press.

Caplicki, E. V. (2005, January). Contractor's License May Not Be Required for Architect to Act as Construction Manager in Nevada. Journal of Professional Issues in Engineering Education and Practice, 68-69.

Coble, R. J. \& Blatter, R. L. (June 1999). Concerns with Safety in Design/Build Process. Journal of Architectural Engineering, 44-48.

Construction Management Association of America. Glossary of Construction Management Terms. Retrieved July 14, 2005 from http://cmaanet.org/glossary.php

Duff, D. \& White, A. (1999). Understanding the Architect's Role in the Construction Process. Retrieved on September 02, 2005 from http://pview.findlaw.com/view/2602268 1?channel=CCC.

General Services Administration. (April 1975). The GSA System for Construction Management. (Public Buildings Service) 
Gharehbaghi, Koorosh \& McManus, Kerry (January 2003). Effective Construction Management. Leadership and Management in Engineering, p. 54-55.

Gibson, E. G. \& Gebken R. J. (September 2003). Design Quality in Pre-Project Planning: Applications of the Project Definition Rating Index. Building Research and Information. Volume 31, Number 5. pg 346-356. Routledge Publishers.

Gordon, R. W., (2004). Professionals and Professionalism: An Overview. Introduction to the Practice of Architecture.

Harder, J. F. (1902, April). Architectural Practice - An Art and a Business. The Brickbuilder, Vol. 11.4, 74-77.

Huovila, P., Leinonen, J., Paevere, P., Porkka, J., \& Foliente, G. (2005) Capturing and Maintaining the Client's Requirements. Systematic Performance Requirements; Management of Built Facilities.

Idaho State Statutes. (2005) Title 54 - Professions, Vocations, and Businesses. (54-4504 Public Works Construction Management Licensing Act). Idaho

Illinois Institute of Technology. (2005). www.iit.edu/ it/delphi.html.

Kimball, B. (1992). The professional ideal in America: A history. Rochester: Rowman \& Littlefield Publishers, Inc.

Kostoff, S. (2000). The Architect: Chapters in the History of the Profession. Berkeley: University of California Press.

Landau, S. B. \& Condit, C. W. (1996). Rise of the New York Skyscraper 1865-1913. New Haven: Yale University Press.

Lauer, Joe (2003). McCarthy Building Companies. Retrieved on February 12, 2005 from http://www.mccarthy.com/peo_loc/contenct/Family-album/pl_fam-alt.html.

Miller, K. \& Burr, K. (2003). Construction/Architecture's Past Forecasts the Future: Estimating and Electronic Documents. ASC Proceedings of the $38^{\text {th }}$ Annual conference, April 11-13, 2002. 315-324.

Odusami, K. T. (April 2002). Perceptions of Construction Professionals Concerning Important Skills of Effective Project Leaders. Journal of Management in Engineering. Vol. 18, No. 2, 61-67.

Oualline, J. (2004). Design-Build: The Benefit of Integration. Retrieved August 23, 2005 from http://www.3di.com. 
Sapers, C. M. (1984). The Liability of Architects and Engineers in Nineteenth-Century America. Journal of Architectural Education, Vol. 41, No. 2, 39-45.

Starr, P. (1982). The social transformation of American medicine. Basic Books Publishers.

Swann, W. (1977). The late middle ages. Ithaca, NY: Cornell University Press.

Taylor, M. J. (March 2000). Return of the Master Builder. Civil Engineering. Vol 70, Issue 3, 40 .

Terry, Joel and Hebblewaite, Kevin (2003). EDI. Retrieved on February 12, 2005 from http://www.ediltd.com/html/the bridging_method.html

Thomsen, C. (1999, April-May). The $21^{\text {st }}$ Century Master Builder. Military Engineer, Vol. 91.

Thomsen, C. (2002). Integrating Architecture, Engineering and Construction Services. Retrieved August 23, 2005 from http://www.3di.com.

Thomsen, C. \& Wells, J. (2005). Rice University Case Study: Excellent architecture on time and in budget. Case study researched for 3D/International, Inc.

Thomsen, C. \& Wells, J. (2005). Target Corporation Case Study. Case study researched for $3 \mathrm{D} /$ International, Inc.

Tulacz, Gary J (2004). The Top 100 Construction Managers-at-Risk. McGraw Hill Construction ENR.

Widener, C. R. (2000). The Next Generation Architect: Using CM to take control of Design and Construction. Presented at the AIA Conference: Springfield, OH.

Woods, M. N. (1999). From Craft to Profession: The Practice of Architecture in Nineteenth-Century America. Berkeley \& Los Angeles: University of California Press.

Yates, J. K. \& Battersby, L. C. (2003, November/December). Master Builder Project Delivery System and Designer Construction Knowledge. Journal of Construction Engineering and Management, 635-644. 
APPENDICES 
APPENDIX A

\section{SELECTED PANEL MEMBERS}

Architect - Stephen Ehninger, AIA, Principal Partner - Harris \& Associates, Concord, CA.

Architect - Dave Hart, FAIA, Architect of the Utah State Capitol, Salt Lake City, UT.

General Contractor - Dave Layton, President and CEO of Layton Construction, Salt Lake City, UT.

General Contractor - Jim Allison, Vice President - Big-D Construction, Salt Lake, UT.

Engineer - Enayat Nawabi, Principal Partner - ECE Engineering, Salt Lake City, UT.

Engineer - Larry Veigel, Principal Partner - Heath Engineering, Salt Lake City, UT.

Construction Manager - Paul Ernst, Construction Manager of the Utah State Capitol Restoration project, 3D/I.

Sub-Contractor - Andrew Seppi, Vice President - Utah Tile \& Roofing. Salt Lake City, UT.

Attorney - Lee Novich. Construction Law Group, San Francisco, CA.

Owner - Public - Keith Stepan, Director of the Utah State Division of Facilities

Construction and Management (DFCM). Salt Lake City, UT.

Owner - Private - Warren Jones, Director of Facilities Planning at Brigham Young University. Provo, UT.

Banker - Brad Starks, Director of Construction Loans Division, Orem, UT.

Developer - Lynn Woodbury - Director of the New Construction Division, Woodbury Corporation. 


\section{APPENDIX B \\ DELPHI ROUNDS \\ The Role of the Architect: \\ Changes of the Past, Practices of the Present, and Indications of the Future}

\section{Research Questions}

Directions: Read the following questions, choose the answer that you feel is most accurate and type in the corresponding letter on the line to the left of the question. If you feel that the most accurate answer is not available, select "other" and write your answer on the blank line provided. If you have any questions or problems with this document, contact Chad Jones at (801) 597-1832 immediately.

\section{Historical Background}

1. The role/responsibility of the architect has changed throughout history. In American history, which period do you feel has seen the most dramatic changes?
a. $17^{\text {th }}$ century
b. $18^{\text {th }}$ century
c. $19^{\text {th }}$ century
d. $20^{\text {th }}$ century
e. Other:

2. "Architect" is defined by the Merriam-Webster Dictionary as " 1 ) a person who designs buildings and advises in their construction 2) a person who designs and guides a plan or undertaking.” This definition is:
a. Very accurate
b. Somewhat accurate
c. Somewhat inaccurate
d. Very inaccurate
e. Other:

3. Historically, an architect has been familiar with all aspects of the construction process and able to effectively create the construction details and documents necessary for construction. With the complexity of projects and the position of the architect today, is it still possible for the architect to effectively detail the documents?
a. Yes
b. No
c. Other: 


\section{The Current Role/Definition of the Architect and the Construction Process}

4. The current role of the architect is than it was 20 years ago?
a. Very different
b. Somewhat different
c. No different
d. Other:

5. How much influence/involvement should the construction manager have during the design phase?
a. A High level
b. A moderate level
c. A minimum level
d. No influence/involvement
e. Other:

6. Considering all types of delivery methods, please rate the following professionals on a scale of 1 to 5 ( 1 being the lowest and 5 the highest) as to the level of significance to the overall success of the construction project during the construction phase.

Architect

General Contractor

Construction Manager

7. Licensing for architects, in the majority of the states, requires a degree from an NCARB (National Council of Architectural Registration Boards) accredited college program with a curriculum that is outlined by NCARB. Do you feel that students who graduate from an accredited program are adequately educated for a career in architecture?
a. Yes
b. No
c. Other:

8. Which professional is better equipped with tools such as education, training, and experience to properly see a project from beginning to finish?
a. The architect
b. The construction manager
c. Other:

9. Considering all types of delivery methods, has the architect become too specialized, such as a sub-contractor, to oversee a construction project from inception to completion?
a. Yes
b. No
c. Other:

\section{The Factors That Impact the Role of the Architect}

10. Considering all types of delivery methods and all phases of the process, architects will most often experience conflicts of role with which other professional?

a. General Contractor 

b. Construction Manager
c. Owner
d. Engineer
e. Other:

11. Considering all types of delivery methods, the introduction of new professionals, such as construction managers have had on the role of the architect.
a. A large impact
b. A moderate impact
c. Little impact
d. No impact
e. Other:

12. The level of collaboration between the contractor and the architect
a. Should be much higher
b. Should be somewhat higher
c. Is sufficient for the needs of the project
d. Should be somewhat lower
e. Should be much lower
f. Other:

13. What is the main catalyst for contention between the architect and general contractor?
a. Poor communication
b. Project budget
c. Project schedule
d. Different backgrounds and cultures
e. Other:

\section{Legal Concerns}

14. Lawsuits against the architect are
a. Much more frequent
b. Somewhat more frequent
c. No change
d. Somewhat less frequent
e. Much less frequent
f. Other:

15. The laws regarding the architect, and errors and omissions state that errors and omissions are allowed and that the architect is released of liability if he acts with an overall professional standard of skill, knowledge, and judgment. This ruling is
a. Too lenient and should be revised
b. Fair and just
c. Too strict and should be revised
d. Other: today than 30 years ago.

16. The number of errors and omissions, by the architect, in a typical set of construction documents is
a. Too high 

b. Somewhat high
c. Somewhat low
d. Very low
e. Other:

17. The number of errors and omissions, when a construction manager is involved in the design phase is than usual.
a. Much higher
b. Somewhat higher
c. No change
d. Somewhat lower
e. Much lower
f. Other:

\section{Indications Into the Future of the Role of the Architect}

18. Who is more qualified to lead a design-build project?
a. The architect
b. The general contractor
c. The construction manager
d. Other:

19. For owners who build multiple buildings, which of the following would be most effective in saving time and money?

a. Creating standards or guidelines for all of their buildings.

b. Using the same design and construction team on each project.

c. Hiring a construction/program manager to oversee all of the projects.

d. Other:

20. Do you agree with this statement: Fragmentation and specialization are leading to the demise of the art of architecture?
a. Yes
b. No
c. Other:

21. Do you agree with this statement: The role of the architect is clear and heading in a positive direction?
a. Yes
b. No
c. Other:

22. On large-scale projects, it is common to have a design architect who works out the schematic design and a production architect who creates the construction documents. Do you think this trend will become more popular?
a. Yes
b. No
c. Other:

23. In what direction do you see the role/responsibility of the architect going within the next 30 years? Please write in your response in the space below. 


\section{Additional Questions for Rounds Two and Three}

24. Which of the following would be the most suitable definition of the architect today?

a. One who functions as the creator of the building's design.

b. One who functions as the coordinator of the building's design.

c. One who functions as the integrator of the building's design.

d. One who functions as the organizer of the building's design.

e. One who functions as the of the building's design.

25. What is the primary factor that has caused the role of the architect to change in the past 20 years?

a. Rise in liability and lawsuits

b. Lack of hands-on construction experience

c. The involvement of a construction manager

d. Other:

26. What additional education requirements do you think would benefit the architecture graduate student?
a. Business management courses
b. Materials and methods courses
c. Construction techniques courses
d. Other:

27. According to the results of the first round, the introduction of new professionals has had an impact on the role of the architect. Has this been a positive or negative impact?
a. Positive
b. Negative
c. Other: 